\title{
Development of novel cationic chitosan-
} and anionic alginate-coated poly(D,L-lactide-coglycolide) nanoparticles for controlled release and light protection of resveratrol

\author{
This article was published in the following Dove Press journal: \\ International Journal of Nanomedicine \\ 16 October 2012 \\ Number of times this article has been viewed
}

\author{
Vanna Sanna' \\ Anna Maria Roggio' \\ Silvia Siliani' \\ Massimo Piccinini' \\ Salvatore Marceddu² \\ Alberto Mariani ${ }^{3}$ \\ Mario Sechi ${ }^{3}$ \\ 'Porto Conte Ricerche, Alghero, \\ Italy; ${ }^{2}$ Istituto di Scienze delle \\ Produzioni Alimentari (ISPA), \\ Consiglio Nazionale delle Ricerche \\ (CNR), Sezione di Sassari, Italy; \\ ${ }^{3}$ Department of Chemistry and \\ Pharmacy, University of Sassari, \\ Sassari, Italy
}

Background: Resveratrol, like other natural polyphenols, is an extremely photosensitive compound with low chemical stability, which limits the therapeutic application of its beneficial effects. The development of innovative formulation strategies, able to overcome physicochemical and pharmacokinetic limitations of this compound, may be achieved via suitable carriers able to associate controlled release and protection. In this context, nanotechnology is proving to be a powerful strategy. In this study, we developed novel cationic chitosan (CS)- and anionic alginate (Alg)-coated poly(D,L-lactide-co-glycolide) nanoparticles (NPs) loaded with the bioactive polyphenolic trans-(E)-resveratrol (RSV) for biomedical applications.

Methods: NPs were prepared by the nanoprecipitation method and characterized in terms of morphology, size and zeta potential, encapsulation efficiency, Raman spectroscopy, swelling properties, differential scanning calorimetry, and in vitro release studies. The protective effect of the nanosystems under the light-stressed RSV and long-term stability were investigated.

Results: NPs turned out to be spherical in shape, with size ranging from 135 to about $580 \mathrm{~nm}$, depending on the composition and the amount of polyelectrolytes, while the encapsulation efficiencies increased from $8 \%$ of uncoated poly(D,L-lactide-co-glycolide) (PLGA) to 23\% and 32\% of Alg- and CS-coated PLGA NPs, respectively. All nanocarriers are characterized by a biphasic release pattern, and more effective controlled release rates are obtained for NPs formulated with higher polyelectrolyte concentrations. Stability studies revealed that encapsulation provides significant protection against light-exposure degradation, by reducing the trans-cis photoisomerization reaction. Moreover, the nanosystems are able to prevent the degradation of trans isoform and the leakage of RSV from the carrier for a period of 6 months.

Conclusion: Our findings indicated that the newly developed CS- and Alg-coated PLGA NPs are suitable to be used for the delivery of bioactive RSV. The encapsulation of RSV into optimized polymeric NPs provides improved drug loading, effective controlled release, and protection against light-exposure degradation, thus opening new perspectives for the delivery of bioactive related phytochemicals to be used for (nano)chemoprevention/chemotherapy.

Keywords: resveratrol, nanochemoprevention, PLGA, chitosan, alginate, nanoparticles

\section{Introduction}

The research and application of natural polyphenols have recently attracted great interest in functional food, nutraceutical, and pharmaceutical companies, due to their potential health benefits. ${ }^{1-3}$ For example, chemoprevention by using natural products has emerged as an important strategy, with potential to prevent the occurrence of cancer 
by inhibition, reversing, or retarding the carcinogenesis process. ${ }^{4-6}$ Among the polyphenolic compounds, the bioactive phytoalexin trans-(E)-resveratrol (RSV), found in red wine, legumes, berries, peanuts, and pistachios, ${ }^{7}$ has gained considerable attention as a preventive agent of several important pathologies, such as neurodegenerative processes, viral infections, vascular diseases, and cancers. ${ }^{8-12}$ RSV has demonstrated potential cancer chemopreventive properties by suppressing the proliferation process at the initiation, promotion, and progression stages of several cancer cell lines, such as lymphocytes, breast, glia, and skin and prostate tumor cells. ${ }^{12-14}$

Despite promising results in preclinical settings, the extensive use of RSV has met only limited success, largely due to its instability, ${ }^{15}$ poor solubility, ${ }^{16}$ inefficient systemic delivery, and low bioavailability. ${ }^{17} \mathrm{RSV}$ is more biologically active compared to its $c i s(Z)$-isoform, and therefore requires the formulation of a finished protecting product, able to retain the structural integrity of the bioactive molecules until consumption or administration. ${ }^{18}$

In this context, the encapsulation of RSV into polymeric or lipid-based matrices is a major challenge, and nanotechnology represents a powerful strategy. ${ }^{19}$ This approach provides prototypes as carriers/vehicles able to offer a greater surface area and the potential to increase solubility, stability, bioavailability, and controlled release as well as targeted delivery of the encapsulated active agents. ${ }^{20-24}$ Moreover, nanoparticles (NPs) tend to extravasate passively through the leaky vasculature that is characteristic of solid tumors (angiogenic blood vessels in tumor tissues have gaps as large as about $400-800 \mathrm{~nm}$ ), and preferentially accumulate through the enhanced permeability and retention (EPR) effect. ${ }^{25,26}$ The increased drug concentration near the cell membrane generates a concentration gradient that promotes drug influx into the cell. Additionally, NPs are taken up by cells through an endocytosis pathway, thus resulting in a higher cellular uptake of the entrapped drug, thereby enabling them to escape from the effect of P-glycoprotein pumps. ${ }^{27}$

More recently, Siddiqui and Mukhtar introduced a novel concept of "nanochemoprevention" where nanotechnology was exploited to augment the outcome of chemoprevention. ${ }^{23,27,28}$ This proof-of-principle study demonstrated the usefulness of nanoparticulate technology to enhance the efficacy of natural agents, such as (-)-epigallocatechin 3-gallate (EGCG), loaded in polylactic acid-polyethylene glycol (PLA-PEG) NPs in the preclinical setting. ${ }^{23}$

Encapsulation of EGCG as well as related natural polyphenols (ie, curcumin) into NPs increased their inhibitory effect on cancer cell proliferation, also improving their pharmacokinetic properties and bioavailability. ${ }^{29-31}$

Several studies have also been reported on the use of nanotechnology to vehicle RSV. In particular, RSV incorporation into $\mathrm{mPEG}$-poly( $\varepsilon$-caprolactone)-based NPs resulted in significantly higher cytotoxicity against malignant glioma cells compared to an equivalent dose of free biomolecule. ${ }^{32}$

Solid-lipid NPs loaded with RSV also contributed to effectiveness of RSV on decreasing cell proliferation and demonstrated potential benefits for prevention of skin cancer. ${ }^{33}$ Moreover, other authors investigated the effect of RSV incorporated in liposome on the proliferation and ultraviolet B (UVB) protection of cells, in order to enhance the efficacy in the prevention and treatment of human skin disorders caused by excessive exposure to UV radiation. ${ }^{34}$ Among the polymeric materials, poly(D,L-lactide-coglycolide) (PLGA) is a widely used copolymer approved by the FDA for various medical and pharmaceutical applications, such as drug delivery. ${ }^{35-37}$ The combination of PLGA as a hydrophobic polymer and many natural hydrophilic biopolymers like gelatin ${ }^{38}$ or sodium alginate (Alg) provides advantages for both the hydrophilic and the hydrophobic nanoparticulate systems. ${ }^{36,39}$ Chitosan (CS) and Alg are two major naturally occurring polysaccharides with hydrophilic characteristics that have been gaining increasing interest in the biomedical field, and particularly in the drug-delivery area. ${ }^{39} \mathrm{CS}$ is a polycationic polymer that has one amino group and two hydroxylic functionalities in the repeating glycosidic residue. ${ }^{40}$

On the other hand, Alg is an anionic polymer extracted from brown algae, and bears carboxylic acid groups that may introduce negative charge to the polymer at appropriate $\mathrm{pH}$ values. ${ }^{41}$ More recently, these polymers have been used as coating materials to make polyelectrolyte multilayer-charged PLGA NPs, ${ }^{42}$ and to achieve cohesive colloidal gels as scaffold in tissue engineering, ${ }^{43}$ such as to construct composite microspheres. ${ }^{44}$

It is a consistent opinion that the future for efficient RSV delivery lies in the development of innovative formulation strategies able to overcome each of the physicochemical, pharmacokinetic, and metabolic limitations that characterize this compound. ${ }^{19}$

In this study, we examined the feasibility of encapsulating RSV into PLGA NPs coated on the surface with cationic and anionic polymers (Figure 1), in order to obtain suitable drug carriers able to combine protection and controlled release. The NPs were prepared by a solvent-displacement method 


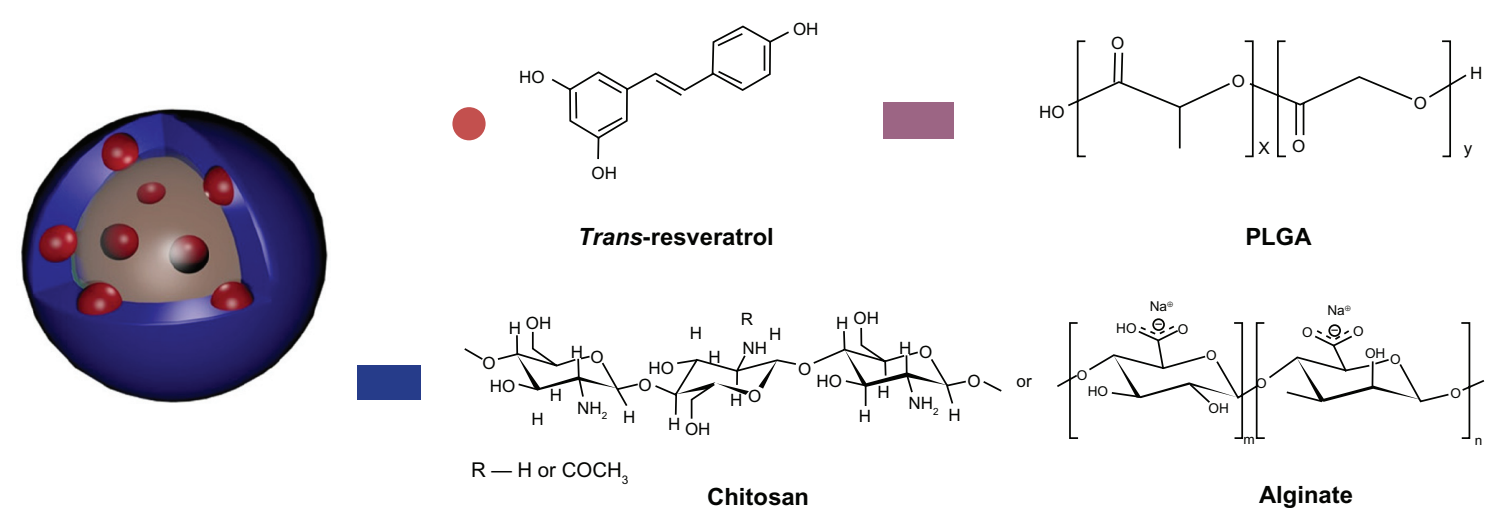

Figure I Chemical structure of RSV, PLGA, CS, and Alg, and schematic representation of the nanoprototypes. Abbreviations: RSV, trans-(E)-resveratrol; PLGA, poly(D,L-lactide-co-glycolide); CS, chitosan; Alg, alginate.

using different amounts of CS and Alg. The influence of coating composition on morphology, size and zeta potential, encapsulation efficiency, swelling capacity and in vitro release was also evaluated. Moreover, the protective effect of the NPs under the light stress of encapsulated RSV in comparison with free compound and long-term stability of nanosystems were investigated and are herein detailed.

\section{Materials and methods} Chemicals and reagents

Poly(D,L-lactide-co-glycolide) (lactide:glycolide $=75: 25$ molar ratio, inherent viscosity $0.14-0.22 \mathrm{dL} / \mathrm{g}$, acid terminated, molecular weight 4000-15,000), CS (low molecular weight, $75 \%-85 \%$ deacetylated chitin, viscosity $200-800 \mathrm{cP}$, $1 \%$ in $1 \%$ acetic acid), alginic acid sodium salt (Alg, medium viscosity $\geq 200 \mathrm{cP}, 2 \%$ ), and RSV were purchased from SigmaAldrich (Steinheim, Germany). All other chemicals were analytical grade and were used without further purification.

\section{Formulation of NPs}

RSV-loaded NPs were prepared by a nanoprecipitation method as previously described, ${ }^{42}$ with minor modification. Briefly, the PLGA polymer and RSV dissolved in $10 \mathrm{~mL}$ acetone were added dropwise into a CS solution $(0.1 \%, 0.25 \%$, and $0.5 \%$ $\mathrm{w} / \mathrm{v}$ acetic acid solution in $0.1 \% \mathrm{v} / \mathrm{v}, 5 \mathrm{~mL})$ or $\mathrm{Alg}(0.1,0.25$, and $0.5 \% \mathrm{w} / \mathrm{v}$ in distilled water, $5 \mathrm{~mL}$ ) under gentle stirring. The set of NPs and their composition is reported in Table 1.

The resulting milky colloidal suspension was evaporated at room temperature to remove the organic solvent. NPs were collected by centrifugation at 13,000 rpm for 10 minutes and washed with water to remove the unencapsulated RSV and residual CS or Alg. PLGA NPs were prepared by adding the polymer and RSV organic solution to water. The obtained NPs were lyophilized for further characterization and utilization.

\section{Morphology, particle-size analysis and zeta potential}

The morphology of NPs was characterized by scanning electron microscopy (SEM) (model DSM 962; Carl Zeiss, Jena, Germany). A drop of NP suspension was placed on an aluminum stub and dried under vacuum for 12 hours. The samples were then analyzed at $20 \mathrm{kV}$ acceleration voltage after gold sputtering, under an argon atmosphere.

Particle size and size distribution of NPs were determined by photon correlation spectroscopy using a Malvern Zetasizer Nano ZS (Malvern Instruments, Malvern, UK), at a temperature of $25^{\circ} \mathrm{C}$ and a scattering angle of $90^{\circ}$.

Zeta potential of the NPs was measured at $25^{\circ} \mathrm{C}$ with a Zeta Plus zeta potential analyzer (Brookhaven Instruments, Holtsville, NY). The samples were diluted with distilled water and sonicated for several minutes before measurement. Data were obtained by the averaging of three measurements.

\section{Raman spectroscopy}

The chemical composition of the RSV, CS, and Alg (raw materials), and PLGA, PLGA-CS, and PLGA-Alg dried NPs was analyzed by Raman spectroscopy (Senterra Raman

Table I Theoretical composition of RSV-loaded NPs

\begin{tabular}{lllll}
\hline Formulation & PLGA & CS & Alg & RSV \\
\hline PLGA & 100 & - & - & $\mathrm{I}$ \\
PLGA-CSI & 100 & 5.0 & - & $\mathrm{I}$ \\
PLGA-CS2 & 100 & 12.5 & - & $\mathrm{I}$ \\
PLGA-CS3 & 100 & 25.0 & - & $\mathrm{I}$ \\
PLGA-AlgI & 100 & - & 5.0 & $\mathrm{I}$ \\
PLGA-Alg2 & 100 & - & 12.5 & $\mathrm{I}$ \\
PLGA-Alg3 & 100 & - & 25.0 & $\mathrm{I}$ \\
\hline
\end{tabular}

Notes: Composition expressed in milligrams (mg); PLGA, PLGA-CSI-3 and PLGAAlgI-3 indicate RSV-loaded NPs.

Abbreviations: CS, chitosan; Alg, alginate; RSV, trans-resveratrol; PLGA, poly(D,Llactide-co-glycolide); NPs, nanoparticles. 
microscope; Bruker Optics, Ettlingen, Germany) using an excitation wavelength of $532 \mathrm{~nm}$ at $5 \mathrm{~mW}$. Raman spectra were recorded by averaging five acquisitions of 5 seconds with a $50 \times$ objective, in the range $180-3200 \mathrm{~cm}^{-1}$.

\section{Differential scanning calorimetry}

Differential scanning calorimetry (DSC) scans of empty and drug-loaded nanoparticles were performed on a DSC Q100 V 9.0 calorimeter (TA Instruments, New Castle, DE). Indium was used to calibrate the instrument. The thermograms of samples were obtained at a scanning rate of $10^{\circ} \mathrm{C} /$ minute in a $30^{\circ} \mathrm{C}-500^{\circ} \mathrm{C}$ temperature range and performed under an $\mathrm{Ar}$ purge (50 $\mathrm{mL} /$ minute). The thermal measurements were carried out on pure RSV, PLGA, CS, Alg, on drug-loaded PLGA-, PLGA-CS-, and PLGA-Alg-coated NPs, and on the physical mixture of PLGA/RSV, PLGA/CS/RSV, and PLGA/Alg/RSV.

\section{Drug-loading content, encapsulation efficiency, and yield of production}

The amount of RSV encapsulated was determined by dissolving an aliquot of NPs $(1.0 \mathrm{mg})$ in $0.1 \mathrm{~mL}$ of methylene chloride. The organic solvent was evaporated and the residue dissolved in $0.1 \mathrm{~mL}$ of mobile phase A:B $(21: 79 \mathrm{v} / \mathrm{v})$, where solvent $\mathrm{A}$ was trifluoroacetic acid (TFA) in water $(0.1 / 99.9 \mathrm{v} / \mathrm{v})$ and solvent B was acetonitrile/TFA/water $(95 / 0.07 / 4.93 \mathrm{v} / \mathrm{v})$. The obtained solution was analyzed by modification of a previously reported high-performance liquid chromatography (HPLC) method ${ }^{45}$ Chromatographic analyses were performed on an HPLC 1200 system (Agilent Technologies, Santa Clara, CA), equipped with a quaternary pump, an autosampler, and a diode array detector. Analyses were carried out using a Jupiter C18 column $(250 \times 2.0 \mathrm{~mm}$, $5-\mu \mathrm{m}$ pore size; Phenomenex, Torrance, CA). The injection volume was $25 \mu \mathrm{L}$ and the analyte was eluted at a flow rate of $0.2 \mathrm{~mL} / \mathrm{minute}$ for an isocratic elution period of 25 minutes. The column was thermostated at $25^{\circ} \mathrm{C}$ and detection was carried out by monitoring the absorbance signals at $306 \mathrm{~nm}$. HPLC was calibrated with standard solutions of $5-50 \mu \mathrm{g} / \mathrm{mL}$ of RSV (correlation coefficient, $R^{2}=0.9999$ ).

The drug-loading content (DLC\%), drug-entrapment efficiency $(\mathrm{EE} \%)$, and yield of NPs (YP\%) were presented by the following equations, respectively:

$\mathrm{DLC} \%=($ Weight of Drug in NPs/Weight of NPs $) \times 100$

$\mathrm{EE} \%=($ Actual RSV Content $/$ Theoretical RSV Content $) \times 100$

YP\% $=($ Weight of NPs Recovered/Weight of Polymer and RSV Fed Initially) $\times 100$

\section{Swelling index (SI)}

The swelling properties of the NPs in phosphate-buffered saline (PBS, pH 7.4) were determined by swelling them to their equilibrium. Accurately weighted amounts of NPs (about $3 \mathrm{mg}$ ) were suspended in PBS solution at $37^{\circ} \mathrm{C}$ for 6 hours. At predetermined time intervals (1, 2, 4, and 6 hours), the swollen NPs were collected by centrifugation at 13,000 rpm for 5 minutes, and the excess surface water was removed carefully using the filter paper. NPs were then immediately weighted on an electronic microbalance. The SI of the specimens was calculated by the following equation: ${ }^{46}$

$$
\begin{aligned}
\mathrm{SI}= & (\text { Weight of Swollen NPs }- \text { Weight of Dry NPs }) / \\
& \text { Weight of Dry NPs }
\end{aligned}
$$

\section{In vitro drug release}

For the in vitro release studies, about $1.0 \mathrm{mg}$ of RSV-loaded NPs were suspended in $1.0 \mathrm{~mL}$ of PBS with different $\mathrm{pH}$ (ie, 6.8 and 7.4) and then incubated at $37^{\circ} \mathrm{C}$ (Thermomixer; HLC BioTech, Bovenden, Germany). At predetermined time intervals, samples were centrifuged at 21,000 rpm for 5 minutes and the isolated NPs were fully dissolved in $1 \mathrm{~mL}$ of mobile phase. The concentration of RSV released from the NPs was determined by HPLC analysis, as described above. Each experiment was performed in triplicate.

\section{RSV protection}

The protective effect of the NPs under the light stress of RSV was investigated and compared with free RSV. Uncoated PLGA, CS- and Alg PLGA-coated NPs (1.0 mg), and free RSV (reference sample) in 5\% ethanol solution were added into a glass flask and exposed for 120 minutes to the UV light set at $254 \mathrm{~nm}$ at a distance of $10 \mathrm{~cm}$. After 120 minutes, NP samples were collected by centrifugation, lyophilized, and the residue was dissolved in $1 \mathrm{~mL}$ of eluent mixture. RSV content was analyzed using the HPLC method previously reported, ${ }^{47}$ with some modifications.

The gradient elution program was: $0-4$ minutes $20 \%$ $\mathrm{B}$ linear increase to $30 \% \mathrm{~B}$; 4-8 minutes linear increase to $40 \% \mathrm{~B} ; 8-12$ minutes linear increase to $65 \%$; $12-16$ minutes linear increase to $80 \% \mathrm{~B} ; 16-20$ minutes linear increase to $95 \% \mathrm{~B} ; 20-24$ minutes linear increase to $100 \% \mathrm{~B} ; 24-26 \mathrm{~min}$ $100 \% \mathrm{~B}$; and 26-28 min linear decrease to $20 \% \mathrm{~B}$, with a final hold at 20\% B until 36 min, where solvent A was TFA in water $(0.1 / 99.9 \mathrm{v} / \mathrm{v})$ and solvent $\mathrm{B}$ was acetonitrile/TFA/ water $(95 / 0.07 / 4.93 \mathrm{v} / \mathrm{v})$. The effect of encapsulation on the stability of RSV was evaluated by the retention percentage 
of trans isomer (ie, RSV), namely the ratio of the content of compound retained in the original one in the samples.

\section{Long-term chemical stability test}

Long-term stability of RSV-loaded NPs was evaluated by monitoring RSV retention and chemical stability during storage. Aqueous NP suspensions were incubated under static conditions at $4{ }^{\circ} \mathrm{C}, 75 \%$ relative humidity, for 6 months. At determined time intervals, the suspensions were centrifuged at 14,000 rpm for 10 minutes, supernatant was removed, and NPs were dissolved in dichloromethane. The amount of RSV was detected by HPLC analysis, as described above.

\section{Statistical analysis}

All data were subjected to one-way analysis of variance (GraphPad Prism, version 5.03; GraphPad, San Diego, CA). Individual differences were evaluated using a nonparametric post hoc test (Tukey's test) and considered statistically significant at $P<0.05$.

\section{Results and discussion Formulation of NPs}

In this study, we developed cationic and anionic PLGA NPs using CS and Alg as surface modifiers in order to allow the encapsulation of RSV, and we investigated the influence of polyelectrolyte coatings on the characteristics of NPs. Nanosystems were obtained by the solvent-displacement method, which involves the precipitation of polymer from an organic solution and the diffusion of the organic solvent in the aqueous medium in the presence or absence of a surfactant. ${ }^{48}$ The coating was performed by precipitation of PLGA NPs in the polyelectrolyte solution, $\mathrm{CS}$ or Alg, which introduced on the surface positive and negative charges, respectively.

\section{Particle-size analysis and zeta potential}

The morphology of nanosystems was investigated by SEM analyses. SEM images of all batches are displayed in Figure 2A-G.

The NPs showed smooth surface and spherical shape, with differences in size depending on the type and amount of polyelectrolytes used on nanoformulation. The uncoated PLGA NPs are characterized by an average diameter of $129.4 \pm 22.6 \mathrm{~nm}$. The coating of PLGA surface with different CS concentrations (ie, 5.0, 12.5, $25.0 \mathrm{mg}$ ) determined a significant increase of particles size, that was found to be $420.82 \pm 22.58,465.25 \pm 39.15$, and $552.56 \pm 30.62 \mathrm{~nm}$ for PLGA-CS1, PLGA-CS2, and PLGA-CS3 NPs, respectively (Figure 3A).
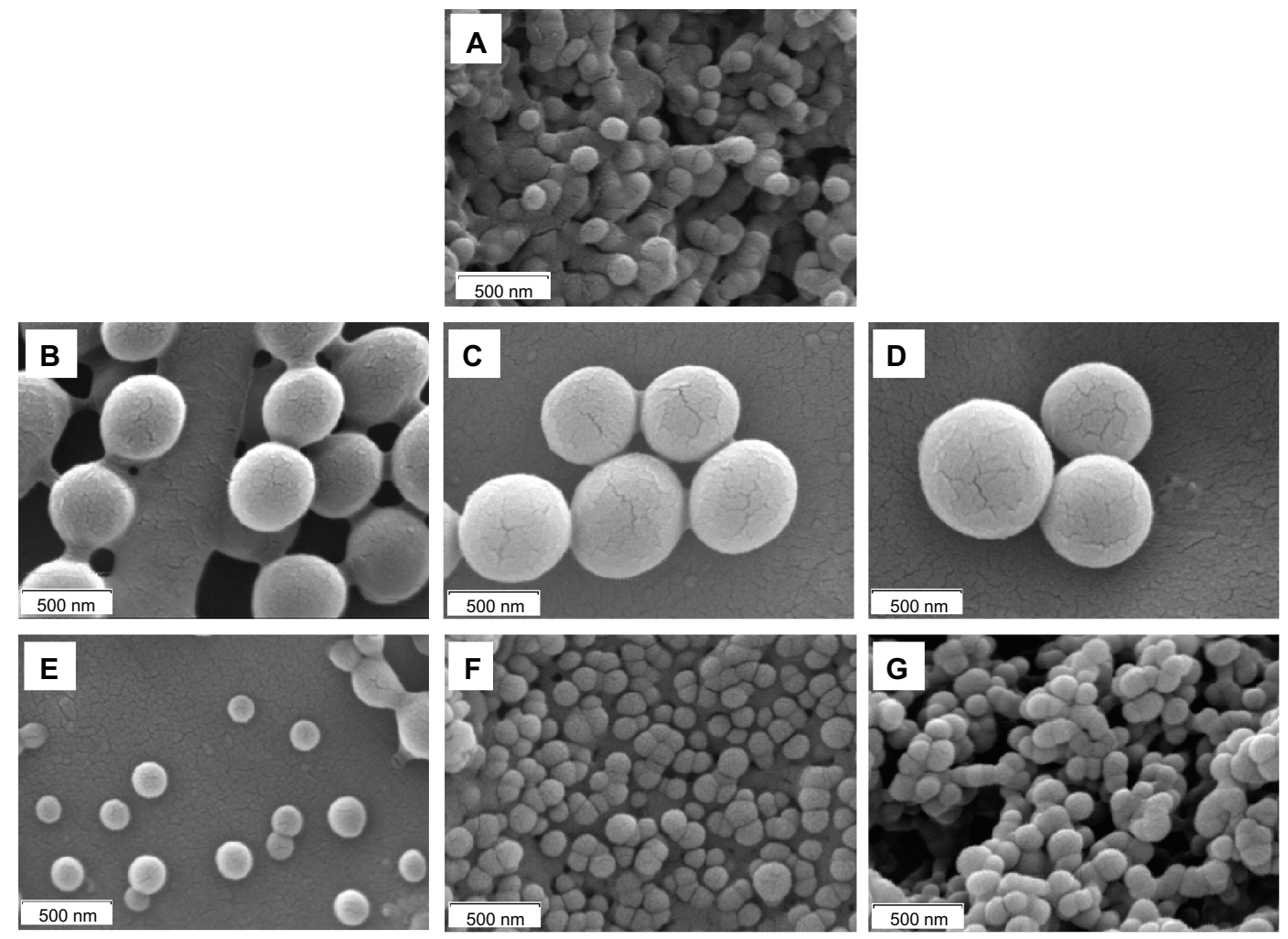

Figure 2 SEM images of PLGA (A), PLGA-CSI (B), PLGA-CS2 (C), PLGA-CS3 (D), PLGA-AlgI (E), PLGA-Alg2 (F), and PLGA-Alg3 (G) RSV-loaded NPs. Abbreviations: RSV, trans-(E)-resveratrol; PLGA, poly(d,I-lactide-co-glycolide; NPs, nanoparticles. 

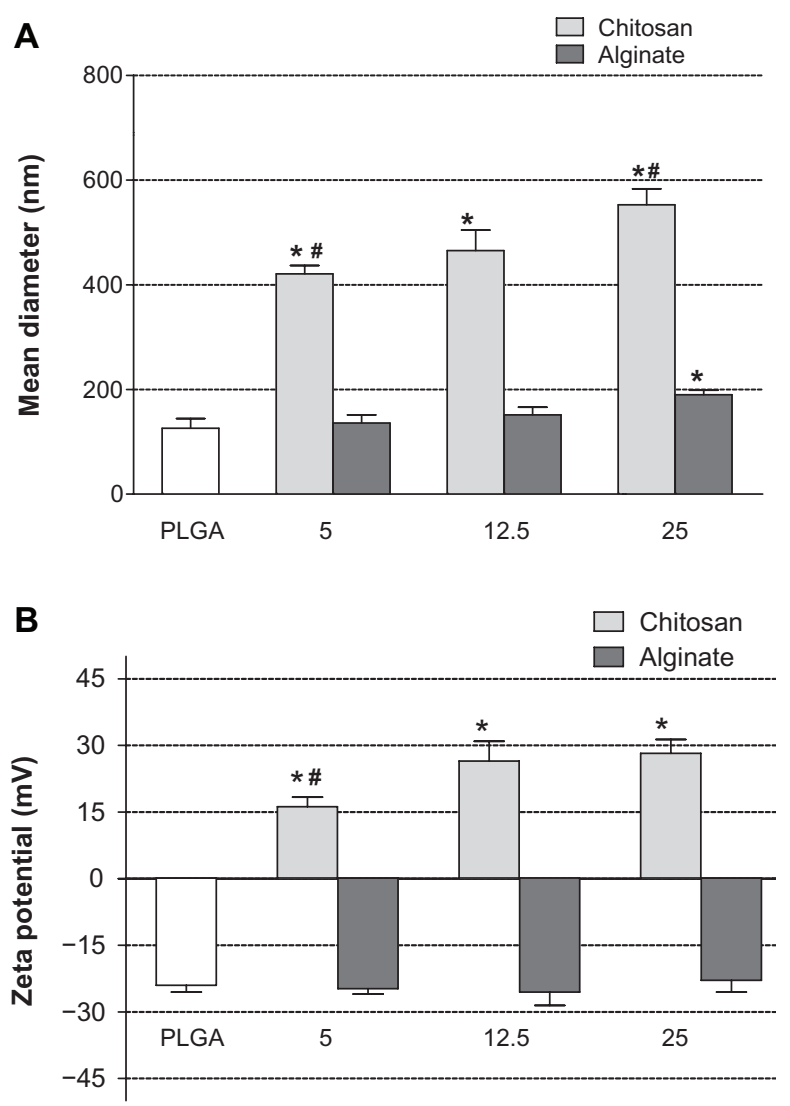

Figure 3 Mean diameter (A) and zeta potential (B) of uncoated PLGA NPs (PLGA) and NPs coated with different amounts $(5.0,12.5$, and $25.0 \mathrm{mg})$ of CS and Alg. Notes: *Significantly different from the PLGA; " significantly different from other CS-coated NPs.

Abbreviations: PLGA, poly(d,I-lactide-co-glycolide; NPs, nanoparticles.

PLGA-CS3 NPs obtained using the highest concentration of CS resulted in significantly larger NPs in regard to NPs produced with lower CS amount (eg, PLGA-CS1, $5.0 \mathrm{mg}$, $P<0.05$ ), suggesting that particle size is related to the concentration of CS used in the particle preparation.

On the other hand, the precipitation of PLGA in Alg solution at different concentrations did not influence particle size with respect to the uncoated PLGA nanosystems. The mean diameter of Alg-coated NPs was only significantly increased for PLGA-Alg3 (190.01 $\pm 8.71 \mathrm{~nm})$, prepared with $25.0 \mathrm{mg}$ Alg, compared to uncoated PLGA NPs $(P<0.05)$. Besides, all formulations were characterized by polydispersity index ranging from 0.27 to 0.38 and exhibited a unimodal particle-size distribution, typical of monodispersed systems.

The differences in size observed in the coated NPs can be mainly related to the different physicochemical properties of CS and Alg polymers, which influence the absorption mechanism on the surface of the polymeric nanoprototypes. In fact, it is well known that the PLGA particle coating with surfactant or polymers is a complex interfacial phenomenon that involves physical adsorption and/or electrostatic interactions between the polymer chains and the coating material. During nanoprecipitation into polyelectrolyte solutions, the electrostatic attraction was proposed as the predominant mechanism, especially in the formation of the first monomolecular adsorption layer. ${ }^{49}$

More specifically, since the protonated amino groups of CS provide opportunities of intermolecular hydrogen bonding with carboxylic end groups of PLGA, the adsorption of CS on the surface of PLGA continues even though a positively charged surface has been achieved, in which hydrogen bonds or Van der Waals forces can be involved. ${ }^{50}$ The subsequent layers of CS may perhaps be adsorbed on the first layer by the physical mechanism. On the contrary, the electrostatic interactions were reduced with anionic $\mathrm{Alg}$, and in this case the coating mechanism could be mainly attributed to physical adsorption on the surface of PLGA. As coating with 5 and $12.5 \mathrm{mg}$ of Alg did not determine a significant increase in mean diameter of NPs, a lower amount of Alg was expected to coat on the surface of a particle compared to $\mathrm{CS}$, due to the large surface-to-volume ratio of the particles. Additionally, it is noted that polyelectrolytes can change their conformation depending on the solution concentration. ${ }^{51,52}$ In fact, in diluted solution the polymer chains are expanded, while in concentrated solution the interchain interactions of polyelectrolyte dominate over intrachain ones. On the basis of these considerations, we can hypothesize the formation of a more compact structure of coating layer in the PLGA-Alg3 NPs with respect to PLGA-Alg1 and PLGA-Alg2 NPs.

The efficiency of NP surface modification can be measured by estimating the zeta potential of the aqueous suspension containing NPs. The surface charge values may be positive or negative depending upon the nature of the polymer or the material used for surface modification. ${ }^{53}$

As shown in Figure 3B, the zeta potential of the uncoated PLGA NPs was negative ( $-24 \pm 1.5 \mathrm{mV})$, as expected, because of the carboxyl end groups on PLGA. Otherwise, all CS-coated NPs were electropositive, confirming the presence of such polymer on the PLGA surface. Zeta potential significantly increased $(P<0.05)$ with CS concentration from 16.2 \pm 2.1 for PLGACS1 to $26.5 \pm 4.4 \mathrm{mV}$ for PLGA-CS2. The further addition of the polymer did not significantly affect the zeta potential, thus suggesting that a steady surface charge was reached.

On the other hand, the zeta potential of Alg-coated NPs was negative and ranged from $-22.9 \pm 2.7$ to $-26.2 \pm 2.2 \mathrm{mV}$, with no significant differences between different batches. This finding can be probably related to the low amount of Alg that 
coats the surface of NPs. Moreover, due to a constant apparent surface charge per unit area (for the exposed carboxyl groups), the layers beyond the first few do not increase the zeta potential. $^{49}$

\section{Drug loading, encapsulation efficiency, and yield of production}

Figure $4 \mathrm{~A}$ and $\mathrm{B}$ shows the dependence of drug-loading content and encapsulation efficiency of NPs on the composition and the amount of polyelectrolytes used. In general, the RSV encapsulation efficiency in the uncoated PLGA NPs $(8.36 \% \pm 0.27 \%)$ was significantly lower $(P<0.05)$ with respect to coated formulations. This suggests that during the precipitation process, only a low amount of RSV can be entrapped into PLGA matrix.

Previous studies on PLGA NPs revealed that the hydrophobic polymer does not promote an efficient loading of hydrophilic molecules, as well as several peptidic compounds. ${ }^{54}$ To improve the drug-encapsulation properties
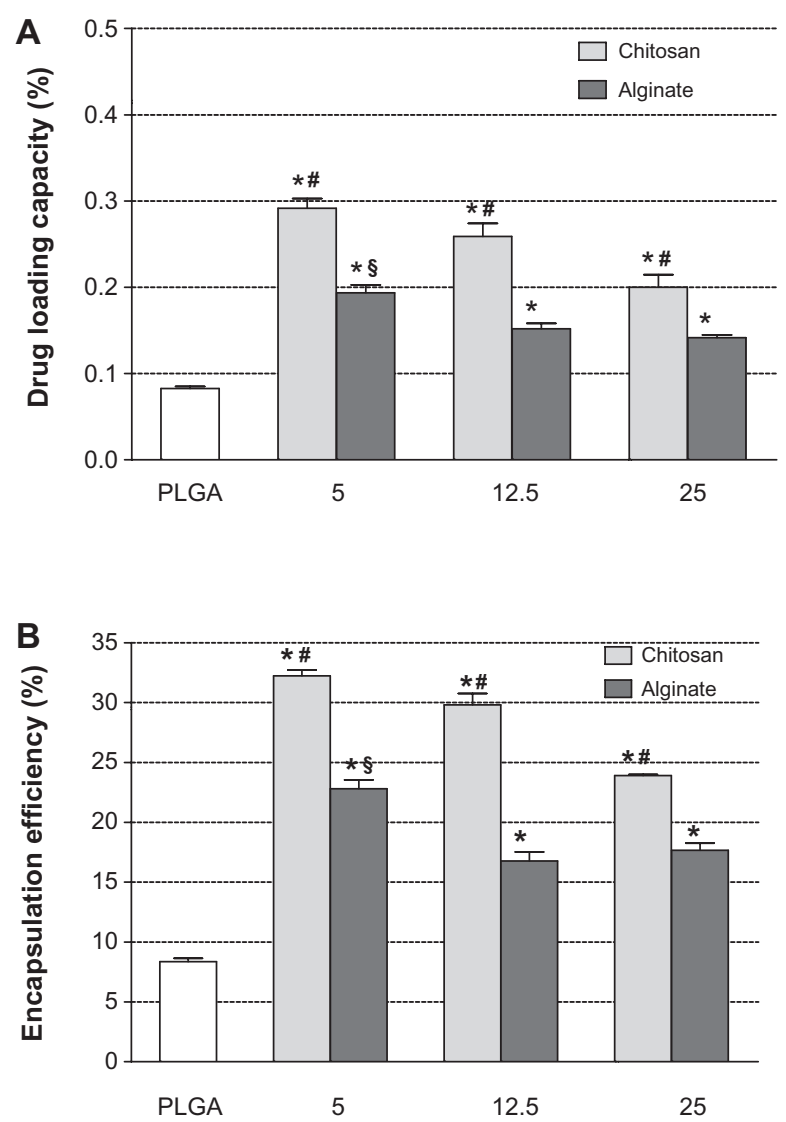

Figure 4 RSV loading content (A) and encapsulation efficiencies (B) of uncoated PLGA NPs and nanosystems coated with different amounts (5.0, 12.5, and $25.0 \mathrm{mg}$ ) of CS and Alg.

Notes: *Significantly different from the PLGA; "significantly different from other CS-coated NPs; §significantly different from other Alg coated-NPs.

Abbreviations: RSV, trans-(E)-resveratrol; PLGA, poly(d,I-lactide-co-glycolide); CS, chitosan; Alg, alginate; NPs, nanoparticles. of PLGA NPs, a possible strategy consists in the modification of the PLGA surface by coating with stabilizing hydrophilic bioadhesive polymers or surfactants. ${ }^{55}$ In the present study, we highlighted that cationic CS and anionic Alg coating on PLGA NPs determined a significant improvement in RSV entrapment efficiency.

As can be seen in Figure 4B, the EE\% values ranged from about $32 \%$ for PLGA-CS 1 to about $24 \%$ for PLGA-CS3 NPs containing the lowest and the highest CS concentrations, respectively. A similar behavior was observed with batches containing Alg, in which the EE\% was found to be $23 \%$ and $18 \%$ for PLGA-Alg1 and PLGA-Alg3, respectively. The higher loading efficiency of CS- and Alg-coated PLGA NPs could be explained by taking into account the chemical properties of RSV and its affinity for hydrophilic polymers. In fact, the RSV is an amphiphilic molecule, with hydrophobic aromatic rings and hydrophilic phenolic hydroxyl groups. ${ }^{56}$ Because of the presence of multiple hydroxyl groups, RSV can establish extensive hydrogen bonding and thus promote complexation with $\mathrm{CS}$ and $\mathrm{Alg}$ polyelectrolytes capable of making H-bonds. ${ }^{57}$ As a result, during the solvent-evaporation process, the RSV remains embedded between polymeric chains of CS or Alg, and therefore on the coating layer on the PLGA surface. Moreover, the increased encapsulation values of RSV observed in CS-coated NPs with respect to batches containing Alg could be related to the presence of different functional groups $\left(\mathrm{OH}\right.$ and $\left.\mathrm{NH}_{2}\right)$ in $\mathrm{CS}$ that might improve the ionic interactions with RSV, and thus determine a larger percentage of entrapped RSV.

The amount of RSV loaded was found to increase in the presence of lower CS or Alg concentrations. This is due to the increase in the initial RSV-to-polyelectrolyte ratio. Upon further addition of polyelectrolytes, the RSV interacts with a larger number of molecules without leading to an extensive enlargement of the coating layer. Thus, it remains in the aqueous solution and is subsequently washed out during the centrifugation procedure. Furthermore, the yields of production obtained ranged from $50 \%$ to $65 \%$, with the highest values obtained for uncoated PLGA NPs.

\section{Raman spectroscopy}

The qualitative composition of NPs was investigated by Raman spectroscopy. The characteristic peaks obtained from RSV, PLGA, CS, and Alg raw materials (Figure 5A) were compared with the peaks for uncoated PLGA, PLGA-CS3, and PLGAAlg3 RSV-loaded NPs, chosen as examples (Figure 5B).

The spectrum of RSV is characterized by the olefinic band at $995 \mathrm{~cm}^{-1}, \mathrm{C}-\mathrm{O}$ stretching vibrations at $1160 \mathrm{~cm}^{-1}$, 
A

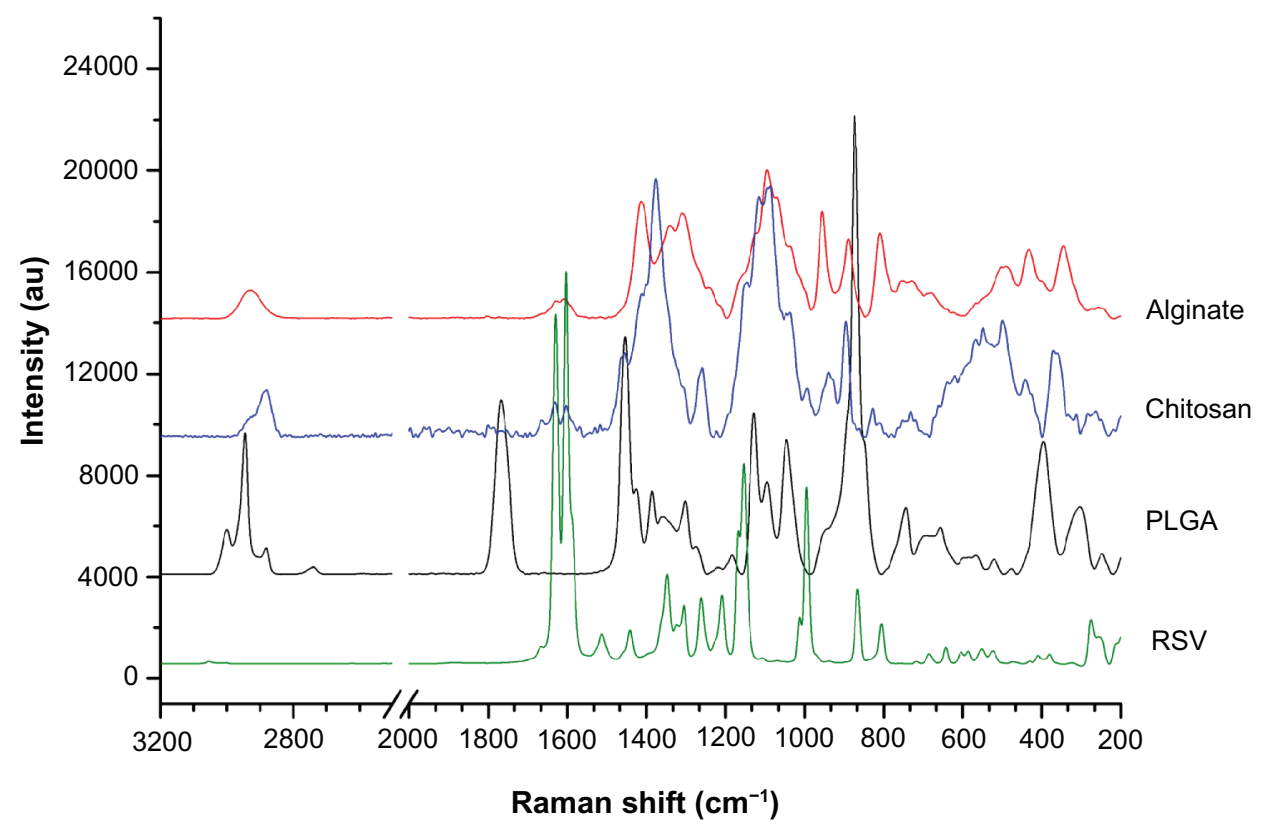

B

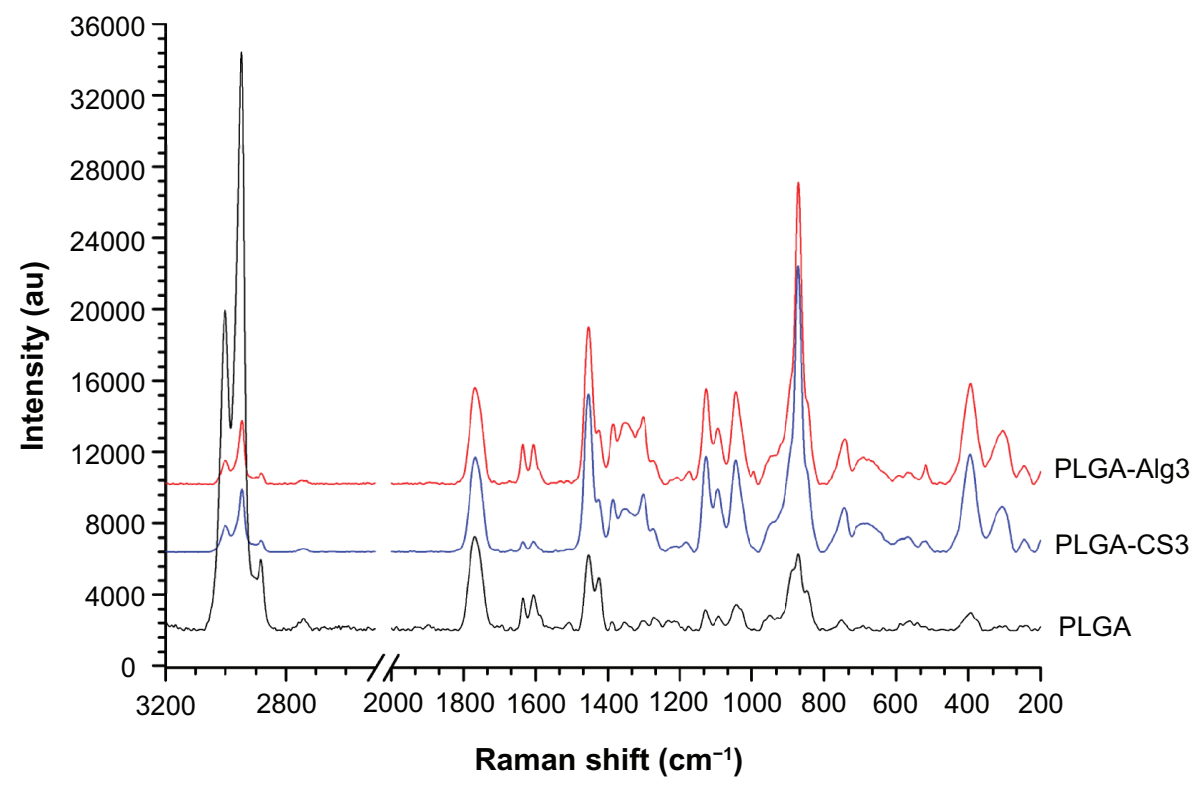

Figure 5 (A) Raman spectra of RSV, PLGA, CS, and Alg (raw materials); (B) PLGA, PLGA-CS3, and PLGA-Alg3 RSV loaded NPs. Abbreviations: RSV, trans-(E)-resveratrol; PLGA, poly(d,I-lactide-co-glycolide); CS, chitosan; Alg, alginate; NPs, nanoparticles.

the intense $\mathrm{C}-\mathrm{C}$ olefinic stretching at $1600 \mathrm{~cm}^{-1}$, and $\mathrm{C}-\mathrm{C}$ aromatic double-bond stretching at $1630 \mathrm{~cm}^{-1}$.

The PLGA spectrum displayed bands at 2882, 2946, and $3000 \mathrm{~cm}^{-1}$ corresponding to $\mathrm{C}-\mathrm{H}$ stretching vibrations, a peak at $1766 \mathrm{~cm}^{-1}$ due to $\mathrm{C}=\mathrm{O}$ bond stretching vibration, peaks at $1130 \mathrm{~cm}^{-1}$ and $1044 \mathrm{~cm}^{-1}$, due to $\mathrm{C}-\mathrm{O}$ stretching. The $\mathrm{C}-\mathrm{H}$ bend was observed at $1453 \mathrm{~cm}^{-1}$. In the spectrum of CS, the peak at $2886 \mathrm{~cm}^{-1}$ was assigned to $\mathrm{C}-\mathrm{H}$ stretching, the absorption band of the carbonyl $(\mathrm{C}=\mathrm{O})$ stretching of amide I at $1630 \mathrm{~cm}^{-1}$, and the bending vibrations of the $\mathrm{N}-\mathrm{H}\left(\mathrm{N}\right.$-acetylated residues, amide II band) at $1600 \mathrm{~cm}^{-1} .58$ The band at $1376 \mathrm{~cm}^{-1}$ belongs to the $\mathrm{N}-\mathrm{H}$ stretching of the amide. The peaks observed at 1090 and $1117 \mathrm{~cm}^{-1}$ were characteristic of $\mathrm{C}-\mathrm{O}$ stretch of $-\mathrm{CH}-\mathrm{OH}$ in cyclic alcohols and of $-\mathrm{CH}_{2}-\mathrm{OH}$ in primary alcohols, respectively. ${ }^{59}$

As far as the characteristics of Alg are concerned, Raman spectroscopy showed a band at $2932 \mathrm{~cm}^{-1}$ due to $\mathrm{C}-\mathrm{H}$ stretching and bands around $1095 \mathrm{~cm}^{-1}$ due to 
$\mathrm{C}-\mathrm{O}-\mathrm{C}$ stretching attributed to its saccharide structure. In addition, the bands at 1617 and $1412 \mathrm{~cm}^{-1}$ were assigned to asymmetric and symmetric stretching peaks of carboxylate salt groups. ${ }^{60}$

The characteristic absorption bands of $\mathrm{C}-\mathrm{C}$ olefinic stretching at $1600 \mathrm{~cm}^{-1}$ and $\mathrm{C}-\mathrm{C}$ aromatic double-bond stretching at $1630 \mathrm{~cm}^{-1}$ of RSV appeared in the loaded uncoated PLGA and CS- and Alg-coated NPs, which probably indicates that RSV molecules were fitted into the polymeric network. ${ }^{61}$

\section{Differential scanning calorimetry}

As shown in Figure 6A, the DSC thermograms of CS and Alg raw materials exhibited the exothermic peaks centered at $320^{\circ} \mathrm{C}$ and $249^{\circ} \mathrm{C}$, respectively, coinciding with the exothermic behavior of the polymer decomposition. ${ }^{62,63}$ In Figure 6B, the DSC scan of pure PLGA showed an endothermic event $\left(57^{\circ} \mathrm{C}\right)$ and an endothermic decomposition peak centered at $372^{\circ} \mathrm{C}$. The DSC curve of RSV showed the characteristic
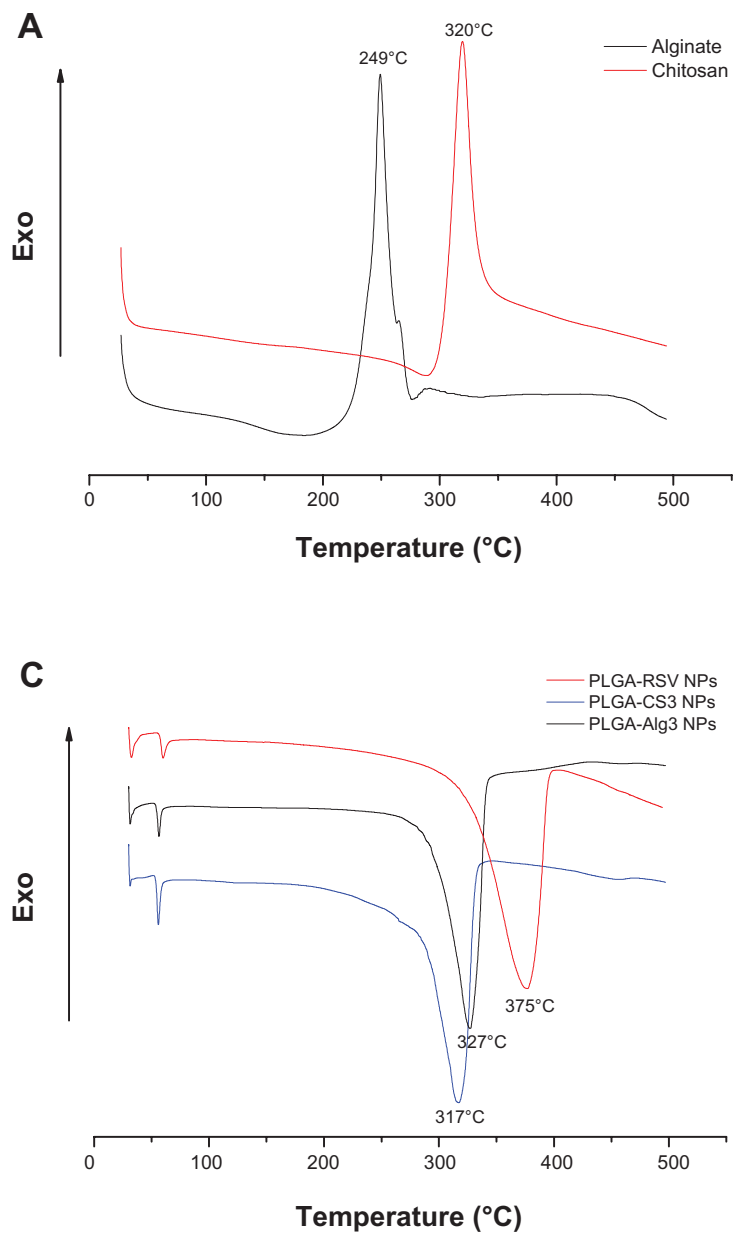

endothermic peaks corresponding to the melting point at $270^{\circ} \mathrm{C}$ and to the glass transition point at $363^{\circ} \mathrm{C} .{ }^{64}$

The disappearance of the RSV melting peak in the DSC thermograms of RSV-loaded NPs (Figure 6C) indicates the absence of the drug crystalline state, suggesting that entrapped RSV is in an amorphous state of a solid molecular dispersion into the polymer matrix. ${ }^{65}$

Furthermore, in the thermogram of RSV-loaded PLGA NPs, the endothermic peak of PLGA appeared at about $375^{\circ} \mathrm{C}$, as observed in the pure PLGA. The scans of PLGACS3 and PLGA-Alg3 NPs, chosen as examples, exhibited a considerable shifting of the endothermic decomposition peak of PLGA from about $375^{\circ}$ to $317^{\circ}$ and $327^{\circ} \mathrm{C}$, respectively. According to Nie et al,$^{66}$ this finding suggests that both CS and Alg were physically blended with PLGA in the NPs.

Additionally, the DSC scans of the physical mixtures of PLGA/CS/RSV and PLGA/Alg/RSV (Figure 6D) confirmed the presence of a shifting of the PLGA decomposition peak with respect to PLGA/RSV, suggesting an intermolecular
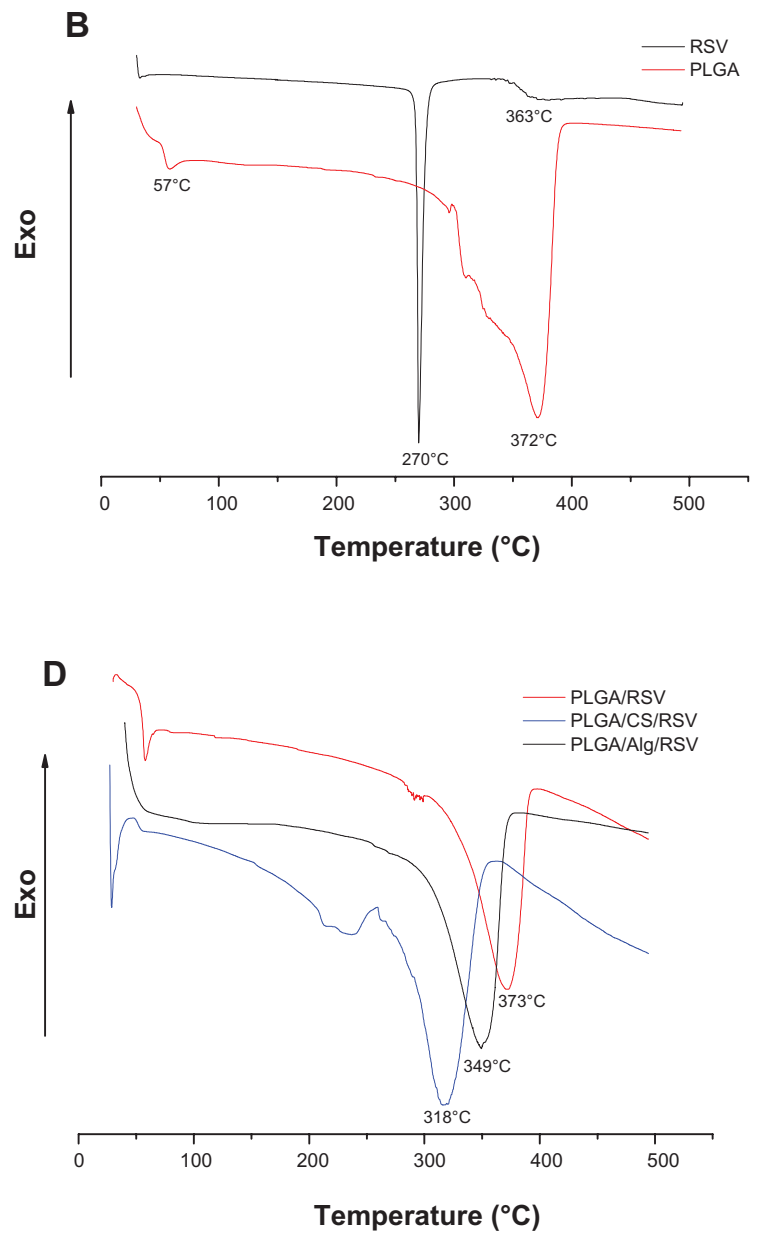

Figure 6 DSC curves of (A) pure CS and Alg, (B) pure RSV and PLGA, (C) uncoated PLGA, PLGA-CS3, and PLGA-Alg3 NPs, and (D) physical mixture of PLGA/RSV, PLGA/ CS/RSV and PLGA/Alg/RSV.

Abbreviations: RSV, trans-(E)-resveratrol; PLGA, poly(d,I-lactide-co-glycolide); CS, chitosan; Alg, alginate; NPs, nanoparticles. 
interaction formed between the components of the systems. $^{67}$

\section{Swelling properties of NPs}

The swelling properties of polymeric NPs can strongly influence their drug-release profiles. ${ }^{37}$ The SI of different batches of NPs was measured as the function of time (until 6 hours), and results are shown in Figure 7A and B.
It was observed that all samples swelled relatively quickly in the first 60 minutes and reached a stable equilibrium within about 2 hours. The plots showed that the swelling capacity of uncoated PLGA NPs (SI about 5) was significantly lower $(P<0.05)$ than that of coated NPs (SI about 8). Since the concentration of polymer used limitedly regulated SI of NPs in both formulations, no significant differences of SI for batches containing CS or Alg were observed. The large

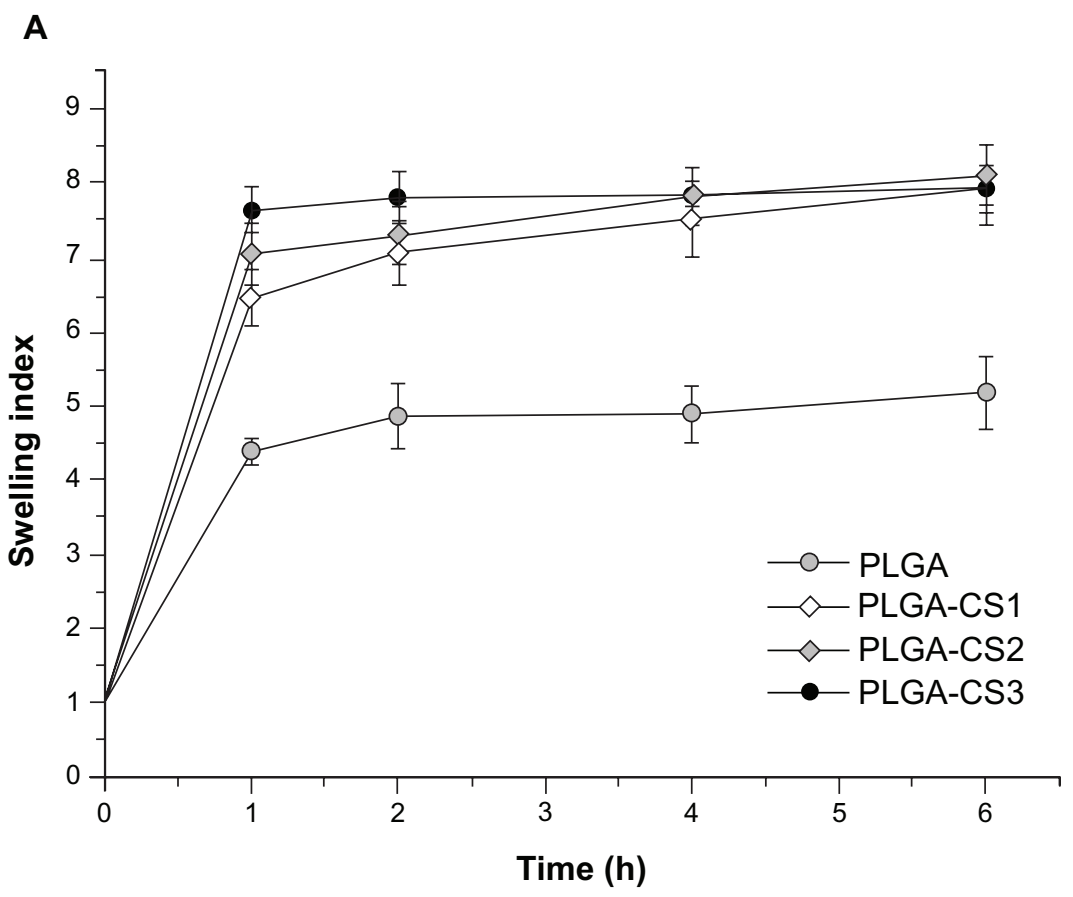

B

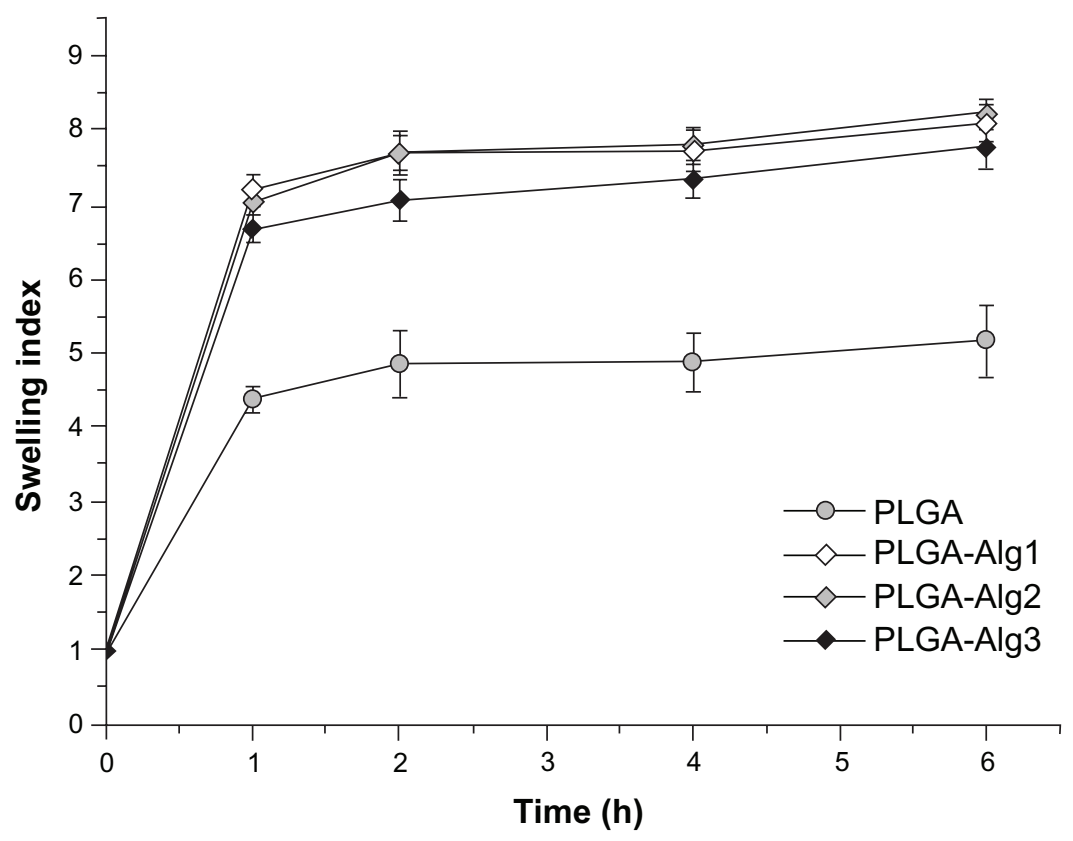

Figure 7 (A and B) Swelling index of different NPs as a function of time in PBS solution $\left(\mathrm{pH} 7.4,37^{\circ} \mathrm{C}\right)$. Abbreviations: PLGA, poly(d,I-lactide-co-glycolide); NPs, nanoparticles; PBS, phosphate-buiffered saline. 
SI and high swelling rate of CS- and Alg-coated NPs can be related to their hydrophilic properties with respect to hydrophobic PLGA polymer.

\section{In vitro drug release}

The in vitro release experiments were performed in PBS at pH 6.8 and 7.4, chosen to simulate both the slightly acidic microenvironment of extracellular fluid in most tumors and the physiological conditions, respectively. ${ }^{68,69}$
All tested formulations showed an overlapping of release profiles in different dissolution media (data not shown), suggesting that the $\mathrm{pH}$ of the medium did not significantly affect the release of RSV from NPs.

Figure $8 \mathrm{~A}$ and $\mathrm{B}$ shows the release profiles of RSV from NPs in PBS solution (pH 7.4) at $37^{\circ} \mathrm{C}$. Formulations are characterized by similar release profiles but different release rates, depending on the properties and the amount of the polyelectrolyte used. On the whole, NPs showed a biphasic

\section{A}

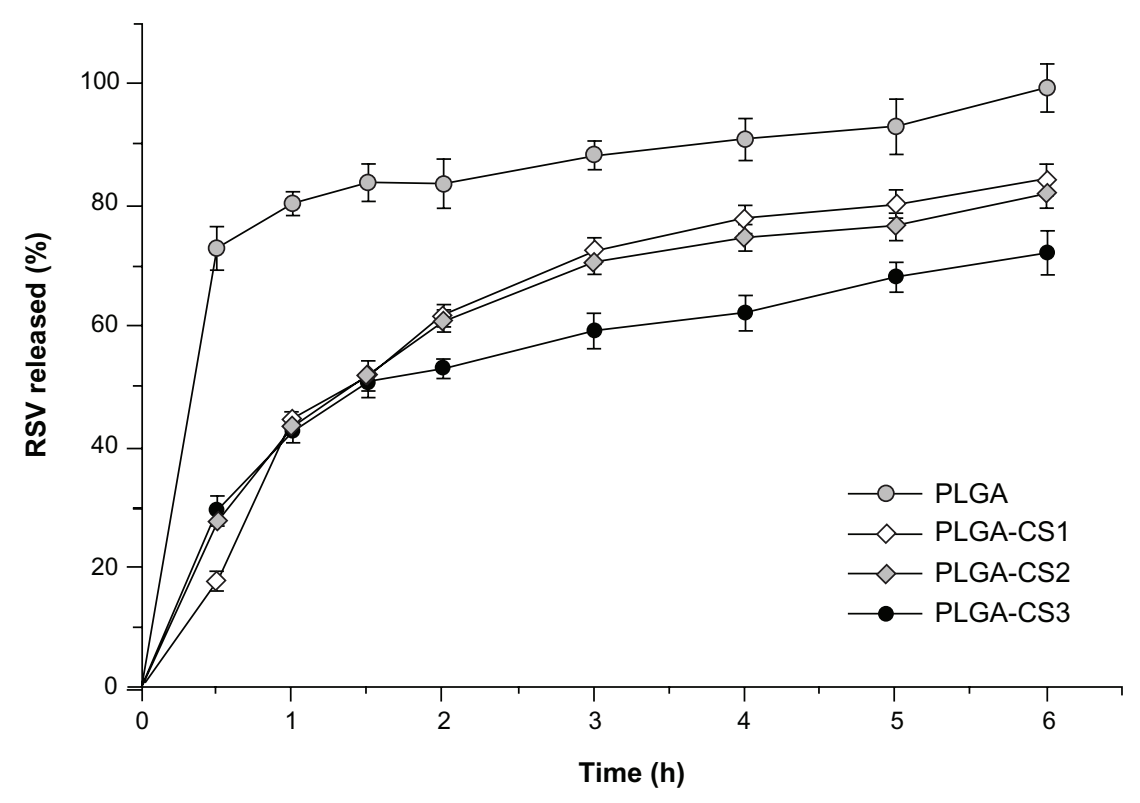

B

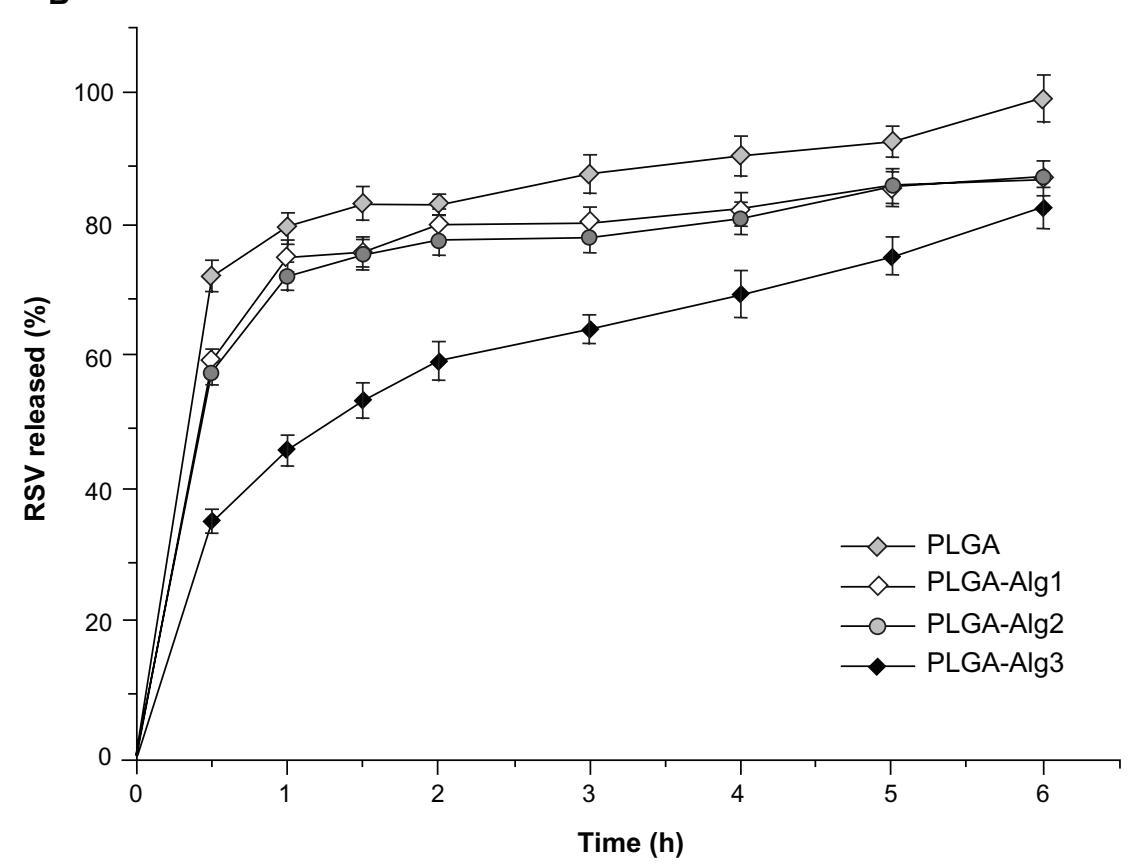

Figure 8 (A and $\mathbf{B}$ ) In vitro release profiles (PBS, pH 7.4, 37 ${ }^{\circ} \mathrm{C}$ ) of RSV from NPs.

Abbreviations: RSV, trans-(E)-resveratrol; PLGA, poly(d,I-lactide-co-glycolide); PBS, phosphate-buffered saline. 
release pattern, where the initial burst of RSV release can be strongly related to the swelling results. When the NPs are exposed to medium, the extended liquid penetration into the systems promotes a fast dissolution of the drug adsorbed, incorporated or weakly bonded onto the surface of NPs with a large surface area.

In the slower-release phase, the RSV was progressively released under the dual influence of diffusion through the polymer matrix and polymer degradation.

PLGA NPs showed a first burst release of RSV (about $70 \%$ ) in the first 30 minutes, followed by a slower and complete release within 6 hours. According to literature data, this finding may be related to small NPs with a relatively large surface, thus resulting in a larger RSV fraction exposed to the leaching medium. Smaller NP size also leads to a shorter diffusion pathway of the matrix-entrapped RSV molecules. ${ }^{70}$

Regarding CS-containing NPs, these showed a similar drug-release profile within the first 1.5 hours, corresponding to about $50 \%$ of RSV released. After 2 hours, PLGA-CS1 and PLGA-CS2 containing $12.5 \mathrm{mg}$ and $25 \mathrm{mg}$ of CS, respectively, showed superimposed release profiles, and released about $80 \%$ of RSV during 6 hours. The increase of CS content to $25 \mathrm{mg}$ (PLGA-CS3) led to a significant decrease in the RSV release rate $(30 \%$ of RSV retained in the 6-hour period). The presence of Alg, 5 and $12.5 \mathrm{mg}$ in PLGA-Alg1 and PLGA-Alg2 NPs, respectively, reduces the release rate compared to PLGA NPs, but results in a significantly higher RSV release with respect to PLGA-CS analogous batches. On the other hand, the release rate of PLGA-Alg3 systems was slightly delayed and comparable to that of PLGA-CS3 NPs during the first 2 hours, followed by a significant improvement of RSV release, corresponding to about $80 \%$ during the 6 hours. It has been claimed

Table 2 Coefficient of determination $\left(R^{2}\right)$ and release exponent (n) of kinetic data analysis of RSV release from different polymeric nanoparticles

\begin{tabular}{|c|c|c|c|c|c|}
\hline \multirow[t]{2}{*}{ Formulation } & \multirow{2}{*}{$\begin{array}{l}\text { Zero- } \\
\text { order } \\
R^{2}\end{array}$} & \multirow{2}{*}{$\begin{array}{l}\text { First- } \\
\text { order } \\
R^{2}\end{array}$} & \multirow{2}{*}{$\begin{array}{l}\text { Higuchi } \\
\overline{R^{2}}\end{array}$} & \multicolumn{2}{|c|}{$\begin{array}{l}\text { Korsmeyer- } \\
\text { Peppas }\end{array}$} \\
\hline & & & & $R^{2}$ & $n$ \\
\hline PLGA & 0.9329 & 0.7643 & 0.9616 & 0.9635 & 0.111 \\
\hline PLGA-CSI & 0.8062 & 0.9452 & $0.907 \mid$ & 0.9605 & 0.297 \\
\hline PLGA-CS2 & 0.8544 & 0.9515 & 0.9420 & 0.9582 & 0.422 \\
\hline PLGA-CS3 & 0.8826 & 0.9542 & 0.9533 & 0.9625 & 0.336 \\
\hline PLGA-AlgI & 0.6973 & 0.8475 & 0.7991 & 0.8635 & 0.129 \\
\hline PLGA-Alg2 & 0.7596 & 0.8931 & 0.8480 & 0.8966 & 0.143 \\
\hline PLGA-Alg3 & 0.9368 & 0.9791 & 0.9827 & 0.9909 & 0.320 \\
\hline
\end{tabular}

Note: PLGA, PLGA-CSI-3, and PLGA-AlgI-3 indicate RSV-loaded NPs.

Abbreviations: PLGA, poly(D,L-lactide-co-glycolide); CS, chitosan; Alg, alginate; RSV, trans-resveratrol; NPs, nanoparticles.

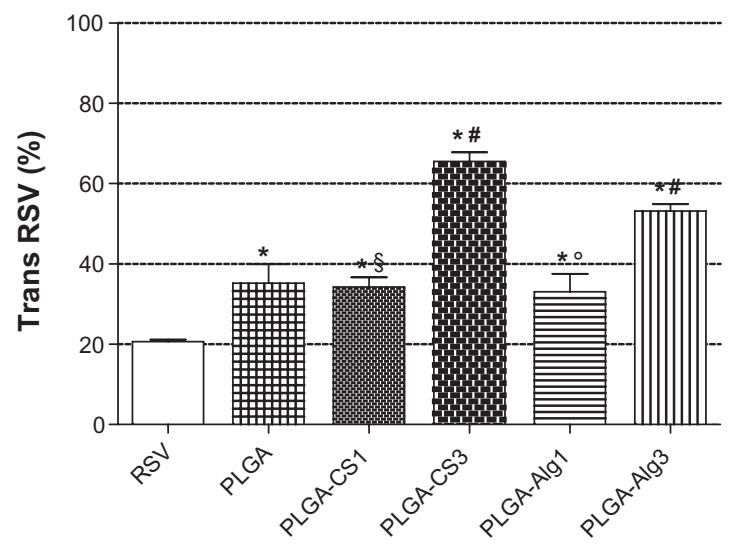

Figure 9 The retention percentage of unencapsulated RSV and uncoated PLGA, PLGA-CSI, PLGA-CS3, PLGA-AlgI, and PLGA-Alg3 NPs exposed to UV lamp for 120 minutes.

Notes: *Significantly different from the free RSV; "significantly different from PLGA; ssignificantly different from other CS-coated NPs; ${ }^{\circ}$ significantly different from other Alg-coated NPs.

Abbreviations: RSV, trans-(E)-resveratrol; PLGA, poly(d,l-lactide-co-glycolide); $\mathrm{CS}$, chitosan; Alg, alginate, NPs, nanoparticles.

that the initial burst release is significantly reduced when using polyelectrolyte layers. ${ }^{71}$ Accordingly, the release rate of RSV from coated NPs was found to decrease with increasing polyelectrolyte concentration, suggesting that the RSV molecules have to pass through an additional layer of diffusional resistance created by the coating material.

In order to investigate the kinetics and mechanism of drug release from NPs, and to confirm that the mechanism governing RSV release from NPs is predominantly diffusion-mediated, the release data were fitted to several mathematical models (zero-order $\left[\mathrm{Q}=\mathrm{k}_{0} \mathrm{t}\right]$, first order $\left[\ln \{100-\mathrm{Q}\}=\ln \mathrm{Q}_{0}-\mathrm{k}_{1} \mathrm{t}\right]$, Higuchi $\left[\mathrm{Q}=\mathrm{k}_{\mathrm{H}} \mathrm{t}^{1 / 2}\right]$, and Korsmeyer-Peppas models). ${ }^{72}$

Table 2 shows the correlation values $\left(R^{2}\right)$ used as an indicator of the best fitting of the models considered for different RSV-NP batches. The $R^{2}$ values for first-order

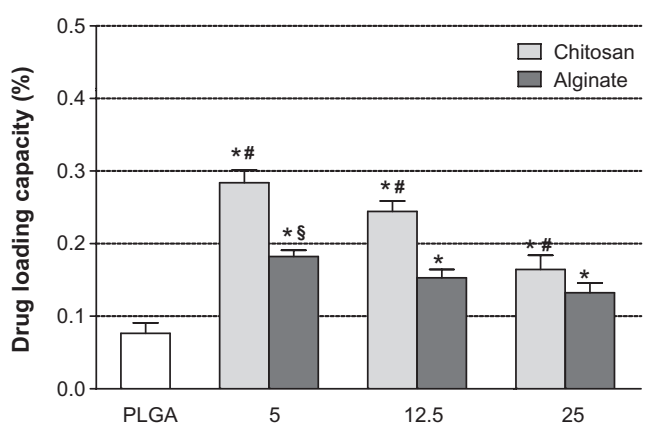

Figure 10 RSV loading content of uncoated PLGA NPs and nanosystems coated with different amounts $(5.0,12.5$, and $25.0 \mathrm{mg})$ of CS and Alg after 6 months of storage at $4^{\circ} \mathrm{C}$.

Notes: *Significantly different from PLGA; " significantly different from other

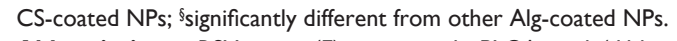

Abbreviations: RSV, trans-(E)-resveratrol; PLGA, poly(d,I-lactide-co-glycolide); CS, chitosan; Alg, alginate; NPs, nanoparticles. 
kinetics of different polymeric NPs (ranging between 0.7643 and 0.9791 ) were greater than that of zero order (ranging between 0.7596 and 0.9368 ) and corresponded with that of Higuchi's square root of time (ranging between 0.7991 and 0.9827 ). Also, to understand the drug-release mechanism, the data were fitted to the Korsmeyer-Peppas exponential model $\mathrm{Mt} / \mathrm{M} \infty=\mathrm{ktn}$, where $\mathrm{Mt} / \mathrm{M} \infty$ is the fraction of drug released after time ' $t$ ', ' $k$ ' is a kinetic constant, and ' $n$ ' is the release exponent that characterizes the different drug-release mechanism. Values of the exponent $\mathrm{n} \leq 0.5$ indicate a Fickian or quasi-Fickian diffusion mechanism, whereas for values $0.5<\mathrm{n}<1$, an anomalous mechanism for drug release occurs. ${ }^{73}$

In all formulations, $\mathrm{n}$ values were found to be in the range of $0.11-0.42$, confirming that the drug release from NPs followed a quasi-Fickian diffusion mechanism.

\section{RSV protection}

RSV naturally occurs in two isoforms, cis and trans, and to date most studies indicate that the trans isomer is biologically more active and more stable than its cis isoform. ${ }^{18} \mathrm{RSV}$ (ie, trans-RSV) is known to be a highly photosensitive compound

A

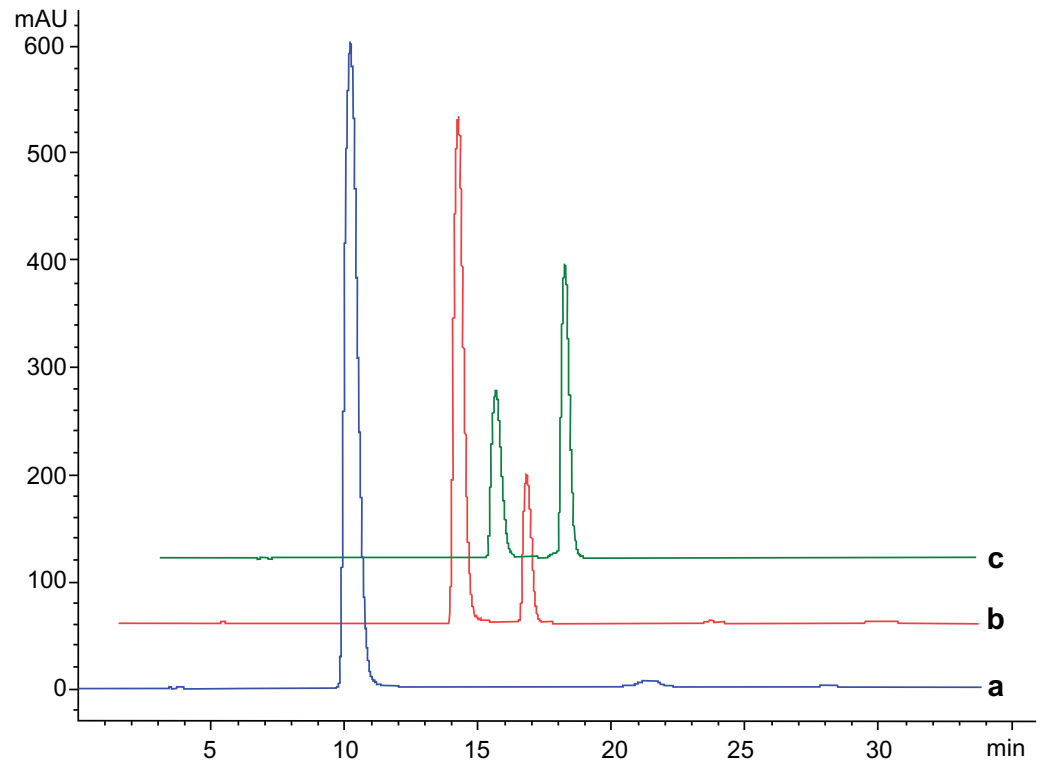

B

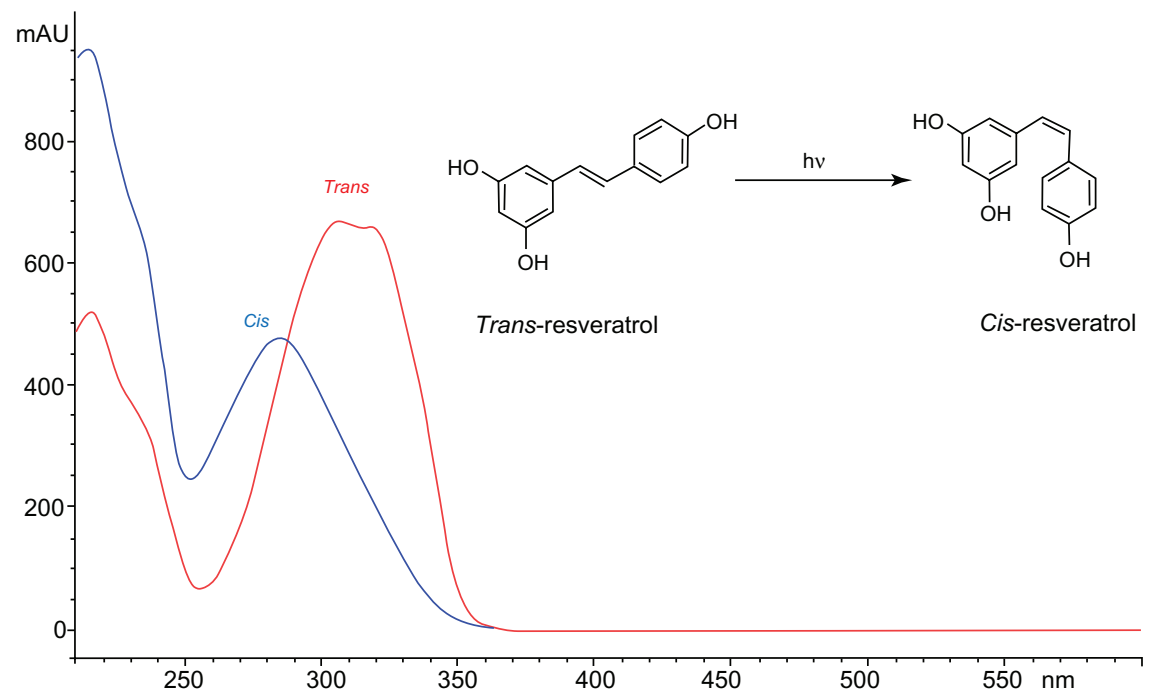

Figure I I (A) HPLC chromatograms of RSV (trans-resveratrol) before (a) and after exposure to UV for 30 minutes (b) and I 20 minutes (c). (B) UV-Vis spectra of trans- and cis-resveratrol conversion induced by UV exposure.

Abbreviations: HPLC, high-performance liquid chromatography; UV-Vis, UV visible. 
and easily degraded by light and heat, which limits its efficacy and application. ${ }^{74}$ In spite of this, we focused our attention on investigating the protective effect of the NPs on degradation of the trans stereoisomeric form of RSV under UV irradiation. As depicted in Figure 11A, before the UV light exposure of RSV, only the peak of trans isoform was detected at 10 minutes (blue line). After 30 minutes of irradiation (red line), a second peak appeared in the chromatogram at about 13 minutes, representing the cis isoform. With further exposure time (120 minutes), the intensity of trans isomer peak decreased, while the peak of $c i s$ increased. The collected UV-visible spectra of two peaks (Figure 11B) was found to be similar to literature data. ${ }^{47}$

As shown in Figure 9, the encapsulation of RSV into NPs largely prevented its degradation with respect to free RSV. After 120 minutes of exposure, only $20 \%$ of trans isoform was detected in the reference sample (unencapsulated RSV), which was significantly reduced if compared with that obtained in the formulations.

In the uncoated PLGA NPs, the retention percentage of RSV was about 35\%. The coating of PLGA NPs with lower polyelectrolyte concentration (PLGA-CS1 and PLGA-Alg1) did not produce a significant increase in protection, probably due to the preferential localization of RSV between polymeric chains of the coating layer, as previously mentioned.

Also, for PLGA-Alg3 and PLGA-CS3, the amount of RSV detected was $53 \%$ and $66 \%$, respectively, suggesting that the larger polyelectrolyte content, with respect to PLGAAlg1 and PLGA-CS1, reduced the RSV fraction exposed to UV light irradiation, thus improving the protection against degradation.

\section{Long-term chemical stability of entrapped RSV}

The chemical integrity of drugs encapsulated in nanoparticles is a fundamental aspect of the overall stability evaluation of formulations, in particular to evaluate the eventual leaking of the drug from the carrier during storage. ${ }^{75}$ The stability of colloidal polymeric carriers depends on their storage conditions (temperature and $\mathrm{pH}$ ), the type and the molecular weight of the polymer used, ${ }^{76}$ and the chemical stability of entrapped drugs. ${ }^{75}$ Consequently, for each specific formulation, the corresponding stability experiments should be performed to assess the quality of the product. In this study, the amount and chemical stability of RSV in NPs stored at $4^{\circ} \mathrm{C}$ was investigated by HPLC for 6 months. As reported in Figure 10, for all formulations the amount of RSV loaded did not change significantly with respect to 0 day (Figure 4A), and no peak was detected due to absorption of cis resveratrol. This finding suggests that NPs showed a negligible release of the encapsulated RSV and are able to prevent the degradation of trans isoform for the long term.

\section{Conclusion}

Our results demonstrate that the newly developed CS- and Alg-coated PLGA NPs are suitable to be used for the encapsulation of bioactive RSV. The amount of cationic or anionic polyelectrolytes employed as surface modifiers resulted in differences in size, surface charge, encapsulation capacity, and in vitro release behavior of RSV-loaded nanoprototypes. Stability studies revealed that encapsulation provides significant protection against light-exposure degradation, thereby contributing to increase the protection of the encapsulated RSV. The translational potential of these novel nanovehicles warrants biological evaluation in several experimental models, eg, focusing on prostate and skin cancer as target diseases. We believe that the insights obtained from this study can contribute to validate the nanoformulation of natural dietary agents, ie, "nanochemoprevention," as a strategy to improve their potential ability to prevent and suppress cancers by intravenous or topical application, as well as to reduce the risk of cancer development in a larger context.

\section{Acknowledgments}

The research activities presented were done within a project agreement with Sardinian Technology Park, Porto Conte Ricerche, Italy. Mario Sechi gratefully acknowledges the Regione Autonoma della Sardegna for financial support of grant CRP-25920, "Development of novel targeted nanodevices for the prevention, diagnosis and treatment of prostate cancer," within the frame of "Legge regionale n 7/2007, promozione della ricerca scientifica e dell'innovazione tecnologica in Sardegna - Annualità 2010." The authors also thank Professor Sergio Uzzau and Dr Tonina Roggio for their organizational support and Dr Paolo Sanna for graphic design.

\section{Disclosures}

The authors report no conflicts of interest in this work.

\section{References}

1. Manach C, Scalbert A, Morand C, Rémésy C, Jiménez L. Polyphenols: food sources and bioavailability. Am J Clin Nutr. 2004;79(5):727-747.

2. Scalbert A, Manach C, Morand C, Rémésy C, Jiménez L. Dietary polyphenols and the prevention of diseases. Crit Rev Food Sci Nutr. 2005; 45(4):287-306. 
3. Scalbert A, Johnson IT, Saltmarsh M. Polyphenols: antioxidants and beyond. Am J Clin Nutr. 2005;81(Suppl 1):215S-217S.

4. Surh YJ. Cancer chemoprevention with dietary phytochemicals. Nat Rev Cancer. 2003;3(10):768-780.

5. Khan N, Afaq F, Mukhtar H. Cancer chemoprevention through dietary antioxidants: progress and promise. Antioxid Redox Signal. 2008;10(3): 475-510.

6. Yang CS, Landau JM, Huang MT, Newmark HL. Inhibition of carcinogenesis by dietary polyphenolic compounds. Annu Rev Nutr. 2001;21:381-406.

7. Frémont L. Biological effects of resveratrol. Life Sci. 2000;66(8):663-673.

8. Sun AY, Wang Q, Simonyi A, Sun GY. Botanical phenolics and neurodegeneration. In: Benzie IFF, Wachtel-Galor S, editors. Herbal Medicine: Biomolecular and Clinical Aspects. 2nd ed. Boca Raton: CRC Press 2011.

9. Baur JA, Pearson KJ, Price NL, et al. Resveratrol improves health and survival of mice on a high-calorie diet. Nature. 2006;444(7117):337-342.

10. Campagna M, Rivas C. Antiviral activity of resveratrol. Biochem Soc Trans. 2010;38(Pt 1):50-53.

11. Yan Y, Gao YY, Liu BQ, Niu XF, Zhuang Y, Wang HQ. Resveratrolinduced cytotoxicity in human Burkitt's lymphoma cells is coupled to the unfolded protein response. BMC Cancer. 2010;10:445.

12. Aggarwal BB, Bhardwaj A, Aggarwal RS, Seeram NP, Shishodia S, Takada Y. Role of resveratrol in prevention and therapy of cancer: preclinical and clinical studies. Anticancer Res. 2004;24(5A):2783-2840.

13. Goswami SK, Das DK. Resveratrol and chemoprevention. Cancer Lett. 2009;284(1):1-6.

14. Ahmad N, Adhami VM, Afaq F, Feyes DK, Mukhtar H. Resveratrol causes WAF-1/p21-mediated G(1)-phase arrest of cell cycle and induction of apoptosis in human epidermoid carcinoma A431 cells. Clin Cancer Res. 2001;7(5):1466-1473.

15. Signorelli P, Ghidoni R. Resveratrol as an anticancer nutrient: molecular basis, open questions and promises. J Nutr Biochem. 2005; 16(8):449-466.

16. Lu Z, Cheng B, Hu YL, Zhang YH, Zou GL. Complexation of resveratrol with cyclodextrins: solubility and antioxidant activity. Food Chem. 2009;113(1):17-20.

17. Juan ME, Buenafuente J, Casals I, Planas JM. Plasmatic levels of transresveratrol in rats. Food Res Int. 2002;35(2):195-199.

18. Munin A, Edwards-Lévy F. Encapsulation of natural polyphenolic compounds; a review. Pharmaceutics. 2011;3(4):793-829.

19. Amri A, Chaumeil JC, Sfar S, Charrueau C. Administration of resveratrol: what formulation solutions to bioavailability limitations? J Control Release. 2012;158(2):182-193.

20. Zhang L, Gu FX, Chan JM, Wang AZ, Langer RS, Farokhzad OC. Nanoparticles in medicine: therapeutic applications and developments. Clin Pharmacol Ther. 2008;83(5):761-769.

21. Byrne JD, Betancourt T, Brannon-Peppas L. Active targeting schemes for nanoparticle systems in cancer therapeutics. Adv Drug Deliv Rev. 2008;60(15):1615-1626.

22. Ranganathan R, Madanmohan S, Kesavan A, et al. Nanomedicine: towards development of patient-friendly drug-delivery systems for oncological applications. Int J Nanomedicine. 2012;7: 1043-1060.

23. Siddiqui IA, Adhami VM, Bharali DJ, et al. Introducing nanochemoprevention as a novel approach for cancer control: proof of principle with green tea polyphenol epigallocatechin-3-gallate. Cancer Res. 2009; 69(5):1712-1716.

24. Sanna V, Pintus G, Roggio AM, et al. Targeted biocompatible nanoparticles for the delivery of (-)-epigallocatechin 3-gallate to prostate cancer cells. J Med Chem. 2011;54(5):1321-1332.

25. Hobbs SK, Monsky WL, Yuan F, et al. Regulation of transport pathways in tumor vessels: role of tumor type and microenvironment. Proc Natl Acad Sci U S A. 1998;95(8):4607-4612.

26. Sanna V, Sechi M. Nanoparticle therapeutics for prostate cancer treatment. Maturitas. 2012;73(1):27-32.
27. Sanna V, Roggio AM, Posadino AM, et al. Novel docetaxel-loaded nanoparticles based on poly(lactide-co-caprolactone) and poly(lactide-coglycolide-co-caprolactone) for prostate cancer treatment: formulation, characterization and cytotoxicity studies. Nanoscale Res Lett. 2011;6(1):260.

28. Siddiqui IA, Mukhtar H. Nanochemoprevention by bioactive food components: a perspective. Pharm Res. 2010;27(6):1054-1060.

29. Siddiqui IA, Adhami VM, Chamcheu JC, Mukhtar H. Impact of nanotecnology in cancer: emphasis on nanochemoprevention. Int $J$ Nanomedicine. 2012;7:591-605.

30. Sanna V, Sechi M. Nanoparticle therapeutics for prostate cancer treatment. Nanomedicine. 2012;8 Suppl 1:S31-S36.

31. Siddiqui AI, Shukla Y, Mukhtar H. Nanoencapsulation of natural products for chemoprevention. J Nanomed Nanotechnol. 2011; 2:104e.

32. Shao J, Li X, Lu X, et al. Enhanced growth inhibition effect of resveratrol incorporated into biodegradable nanoparticles against glioma cells is mediated by the induction of intracellular reactive oxygen species levels. Colloids Surf B Biointerfaces. 2009;72(1):40-47.

33. Teskac K, Kristl J. The evidence for solid lipid nanoparticles mediated cell uptake of resveratrol. Int J Pharm. 2010;390(1):61-69.

34. Caddeo C, Teskac K, Sinico C, Kristl J. Effect of resveratrol incorporated in liposomes on proliferation and UV-B protection of cells. Int J Pharm. 2008;363(1-2):183-191.

35. Shive MS, Anderson JM. Biodegradation and biocompatibility of PLA and PLGA microspheres. Adv Drug Deliv Rev. 1997;28(1):5-24.

36. Makadia HK, Siegel SJ. Poly lactic-co-glycolic acid (PLGA) as biodegradable controlled drug delivery carrier. Polymers. 2011;3(3): 1377-1397.

37. Davaran S, Rashidi MR, Pourabbas B, Dadashzadeh M, Haghshenas NM. Adriamycin release from poly(lactideco-glycolide)-polyethylene glycol nanoparticles: synthesis, and in vitro characterization. Int $J$ Nanomedicine. 2006;1(4):535-539.

38. Li SH, Cai SX, Liu B, Ma KW, Wang ZP, Li XK. In vitro characteristics of poly(lactic-co-glycolic acid) microspheres incorporating gelatin particles loading basic fibroblast growth factor. Acta Pharmacol Sin. 2006;27(6):754-759.

39. George M, Abraham TE. Polyionic hydrocolloids for the intestinal delivery of protein drugs: alginate and chitosan - a review. $J$ Control Release. 2006;114(1):1-14.

40. Agrawal P, Strijkers GJ, Nicolay K. Chitosan-based systems for molecular imaging. Adv Drug Deliv Rev. 2010;62(1):42-58.

41. Takka S, Gürel A. Evaluation of chitosan/alginate beads using experimental design: formulation and in vitro characterization. AAPS Pharm Sci Tech. 2010;11(1):460-466.

42. Zhou J, Romero G, Rojas E, Ma L, Moya S, Gao C. Layer by layer chitosan/alginate coatings on poly(lactide-co-glycolide) nanoparticles for antifouling protection and folic acid binding to achieve selective cell targeting. J Colloid Interface Sci. 2010;345(2):241-247.

43. Wang Q, Jamal S, Detamore MS, Berkland C. PLGA-chitosan/PLGAalginate nanoparticle blends as biodegradable colloidal gels for seeding human umbilical cord mesenchymal stem cells. J Biomed Mater Res A. 2011;96(3):520-527.

44. Choi DH, Park CH, Kim IH, Chun HJ, Park K, Han DK. Fabrication of core-shell microcapsules using PLGA and alginate for dual growth factor delivery system. J Control Release. 2010;147(2):193-201.

45. Sun B, Ribes AM, Leandro MC, Belchior AP, Spranger MI. Stilbenes: quantitative extraction from grape skins, contribution of grape solids to wine and variation during wine maturation. Anal Chim Acta. 2006; 563(1-2):382-390.

46. Elgindy N, Elkhodairy K, Molokhia A, ElZoghby A. Biopolymeric nanoparticles for oral protein delivery: design and in vitro evaluation. J Nanomed Nanotechnol. 2011;2(3):110.

47. López-Hernández J, Paseiro-Losada P, Sanches-Silva AT, Lage-Yusty MA. Study of the changes of trans-resveratrol caused by ultraviolet light and determination of trans- and cis-resveratrol in Spanish white wines. Eur Food Res Technol. 2007;225:789-796. 
48. Quintanar-Guerrero D, Allemann E, Fessi H, Doelker E. Preparation techniques and mechanism of formation of biodegradable nanoparticles from preformed polymers. Drug Dev Ind Pharm. 1998;24(12): 1113-1128.

49. Guo C, Gemeinhart RA. Understanding the adsorption mechanism of chitosan onto poly(lactide-co-glycolide) particles. Eur J Pharm Biopharm. 2008;70(2):597-604.

50. Mahmoodi M, Khosroshahi ME, Atyabi F. Laser thrombolysis and in vitro study of tPA release encapsulated by chitosan coated PLGA nanoparticles for AMI. Int J Biol Biomed Eng. 2010;4(2):35-42.

51. Michler GH, Baltá Calleja FJ. Part III. Nano- and microcomposites: interphase. In: Karger-Kocsis J, Fakirov S, editors. Nano- and Micromechanics of Polymers Blends and Composites. Cincinnati: Hanser; 2009.

52. Somasundaran P, Mehta SC, Yu X, Krishnakumar S. Cap 6: colloid systems and interfaces stability of dispersions through polymer and surfactant adsorption. In: Birdi KS, editor. Handbook of Surface and Colloid Chemistry. 3rd ed. Boca Raton: CRC Press; 2008.

53. Soppimath KS, Aminabhavi TM, Kulkarni AR, Rudzinski WE. Biodegradable polymeric nanoparticles as drug delivery devices. $J$ Control Release. 2001;70(1-2):1-20.

54. Zheng $\mathrm{CH}$, Gao JQ, Zhang YP, Liang WQ. A protein delivery system: biodegradable alginate-chitosan-poly(lactic-co-glycolic acid) composite microspheres. Biochem Biophys Res Commun. 2004;323(4): 1321-1327.

55. Trimaille T, Pichot C, Delair T. Surface functionalization of poly(D,Llactic acid) nanoparticles with poly(ethylenimine) and plasmid DNA by the layer-by-layer approach. Colloids Surf A Physicochem Eng Asp. 2003;221(1):39-48.

56. Riou V, Vernhet A, Doco T, Moutounet M. Aggregation of grape seed tannins in model wine - effect of wine polysaccharides. Food Hydrocoll. 2002;16(1):17-23

57. Handique JG, Baruah JB. Polyphenolic compounds: an overview. React Funct Polym. 2002;52:163-188.

58. Sankalia MG, Mashru RC, Sankalia JM, Sutariya VB. Reversed chitosan-alginate polyelectrolyte complex for stability improvement of alpha-amylase: optimization and physicochemical characterization. Eur J Pharm Biopharm. 2007;65(2):215-232.

59. Chen SC, Wu YC, Mi FL, Lin YH, Yu LC, Sung HW. A novel pHsensitive hydrogel composed of N,O-carboxymethyl chitosan and alginate cross-linked by genipin for protein drug delivery. J Control Release. 2004;96(2):285-300.

60. Sartori C, Finch DS, Ralph B. Determination of the cation content of alginate thin films by FTIR spectroscopy. Polymer. 1997;38(1): 43-51.

61. Socrates G. Infrared and Raman Characteristic Group Frequencies Tables and Charts. 3rd ed. Chichester: J Wiley \& Sons; 2001.
62. Wan Y, Lu X, Dalai S, Zhang J. Thermophysical properties of polycaprolactone/chitosan blend membranes. Thermochim Acta. 2009; 487(1-2):33-38.

63. Fernández-Hervás MJ, Holgado MA, Fini A, Fell JT. In vitro evaluation of alginate beads of a diclofenac salt. Int J Pharm. 1998;163(1-2): 23-34.

64. Lee CW, Yen FL, Huang HW, et al. Resveratrol nanoparticle system improves dissolution properties and enhances the hepatoprotective effect of resveratrol through antioxidant and anti-inflammatory pathways. J Agric Food Chem. 2012;60(18):4662-4671.

65. Tzeng CW, Yen FL, Wu TH, et al. Enhancement of dissolution and antioxidant activity of kaempferol using a nanoparticle engineering process. J Agric Food Chem. 2011;59(9):5073-5080.

66. Nie H, Lee LY, Tong H, Wang CH. PLGA/chitosan composites from a combination of spray drying and supercritical fluid foaming techniques: new carriers for DNA delivery. J Control Release. 2008;129(3): 207-214.

67. Makraduli L, Crcarevska MS, Geskovski N, Dodov MG, Goracinova K. Factorial design analysis and optimisation of alginate-Ca-chitosan microspheres. J Microencapsul. Epub July 3, 2012.

68. Danhier F, Feron O, Préat V. To exploit the tumor microenvironment: passive and active tumor targeting of nanocarriers for anti-cancer drug delivery. J Control Release. 2010;148(2):135-146.

69. Lee ES, Oh KT, Kim D, Youn YS, Bae YH. Tumor pH-responsive flower-like micelles of poly(L-lactic acid)-b-poly-(ethylene glycol)b-poly(L-histidine). J Control Release. 2007;123(1):19-26.

70. Brigger I, Dubernet C, Couvreur P. Nanoparticles in cancer therapy and diagnosis. Adv Drug Deliv Rev. 2002;54(5):631-651.

71. Tan JP, Wang Q, Tam KC. Control of burst release from nanogels via layer by layer assembly. J Control Release. 2008;128(3):248-254.

72. Mehta AK, Yadav KS, Sawant KK. Nimodipine loaded PLGA nanoparticles: formulation optimization using factorial design, characterization and in vitro evaluation. Curr Drug Deliv. 2007;4(3): 185-193.

73. Korsmeyer RW, Gurney R, Doelker E, Buri P, Peppas NA. Mechanism of solute release from porous hydrophilic polymer. J Pharm Sci. 1983; 15(1):25-35.

74. Orallo F. Comparative studies of the antioxidant effects of cis- and trans-resveratrol. Curr Med Chem. 2006;13(1):87-98.

75. Abdelwahed W, Degobert G, Stainmesse S, Fessi H. Freeze-drying of nanoparticles: formulation, process and storage considerations. $A d v$ Drug Deliv Rev. 2006;58(15):1688-1713.

76. Lemoine D, Francois C, Kedzierewicz F, Preat V, Hoffman M, Maincent P. Stability study of nanoparticles of poly( $\varepsilon$-caprolactone), poly(D,L-lactide) and poly(D,L-lactide-co-glycolide). Biomaterials. 1996;17(22):2191-2197.
International Journal of Nanomedicine

\section{Publish your work in this journal}

The International Journal of Nanomedicine is an international, peerreviewed journal focusing on the application of nanotechnology in diagnostics, therapeutics, and drug delivery systems throughout the biomedical field. This journal is indexed on PubMed Central, MedLine, CAS, SciSearch $\AA$, Current Contents ${ }^{\circledR} /$ Clinical Medicine,

\section{Dovepress}

Journal Citation Reports/Science Edition, EMBase, Scopus and the Elsevier Bibliographic databases. The manuscript management system is completely online and includes a very quick and fair peer-review system, which is all easy to use. Visit http://www.dovepress.com/ testimonials.php to read real quotes from published authors. 